\title{
Dorsal Approach Rhinoplasty
}

\author{
Kenneth R Dubeta
}

\section{Part I: Historical Milestones in Rhinoplasty}

\begin{abstract}
Direct dorsal excision of skin and subcutaneous tissue is employed in rhinoplasty cases characterized by thick rigid skin to achieve satisfactory esthetic results, in which attempted repair by more conventional means would most likely frustrate both surgeon and patient.

This historical review reminds us of the lesson: 'History repeats itself.' Built on a foundation of reconstructive rhinoplasty, modern cosmetic and corrective rhinoplasty have seen the parallel development of both open and closed techniques as 'new' methods are introduced and reintroduced again. It is from the perspective of constant evolution in the art of rhinoplasty surgery that the author presents, in Part II, his unique 'eagle wing' chevron incision technique of dorsal approach rhinoplasty, to overcome the problems posed by the rigid skin nose.
\end{abstract}

Keywords: Dorsal approach rhinoplasty, Eagle wing incision, Rigid skin nose, External approach rhinoplasty, Historical milestones.

How to cite this article: Dubeta KR. Dorsal Approach Rhinoplasty. Int J Otorhinolaryngol Clin 2013;5(1):1-23.

\section{Source of support: Nil}

Conflict of interest: None declared

\section{INTRODUCTION}

Throughout the ages, numerous techniques of altering, correcting and more recently, improving the appearance and function of the nose have been described. Methods of altering the appearance of the nose have been limited only by man's imagination. These have varied from nasal amputation, as a form of punishment, to forms of embellishment such as tattooing, or adornment with precious gems, metals and/or pieces of bone.

With the additional burdens imposed by disease and accidental trauma, the nose has been forced to endure an almost equal number of corrective solutions and 'cures'. Thus, even in ancient times, bandages were being applied to support or straighten the broken nose ${ }^{1}$ (Fig. 1: Perikephalea) and the missing nose was being rebuilt in India with forehead skin flaps. ${ }^{2}$ It has been the portal of entry for innumerable inhalations, regardless of the affliction. Occasionally, it has fallen off because of medications taken by mouth. ${ }^{3}$

It is only within the past one hundred years or so, however, that modern surgical techniques have evolved, permitting actual enhancement of both structural esthetics

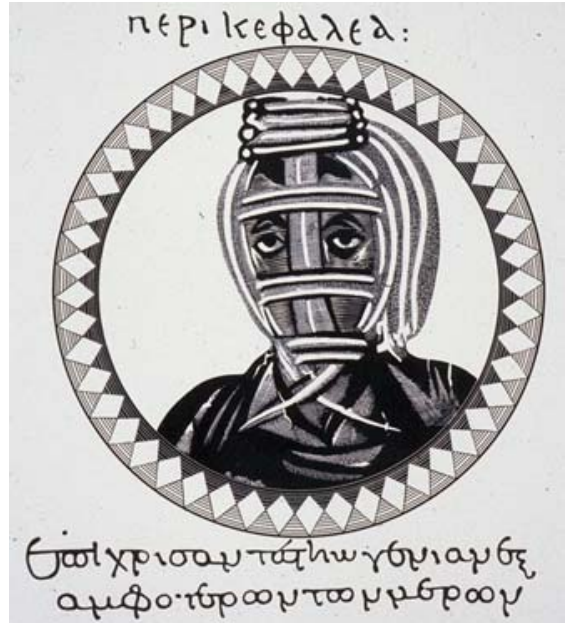

Fig. 1: Ancient Greek 'perikephalea' to support the straightened nose ${ }^{1}$

and functions of the nose. Refinement of these techniques seemingly had to await three antecedent developments; topical vasoconstriction; topical, systemic and local anesthesia; and safe, reliable sources of illumination. The last half of the 20th century has seen the dissemination of two of the most important developments in the history of nasal surgery:

1. Recognition of the key role of the ethmoid sinuses in sinus disease, followed shortly by concomitant development of the sinus endoscope.

2. The open or external approach to rhinoplasty.

With regard to this latter development, it is ironic that rhinoplastic surgeons were themselves responsible for retarding progress in the evolution of esthetic and reconstructive nasal surgery, by restricting visualization of the complicated skeletal infrastructure of the nose through adherence to the conventional closed techniques popularized by Joseph in the first half of this century. Many will still argue that the infrastructure of the nose can be exposed just as well via closed techniques, without 'risking' an external (transcolumellar) scar. But none who are at least familiar with the external approach can deny that the superior exposure provided by this technique facilitates surgical correction of the more challenging nasal asymmetries and deformities.

There remains a group of 'problem noses', however, in which even the transcolumellar external approach will prove 
inadequate. These noses are characterized by bulky and/or rigid skin, due to heredity, scarring or disease of the cutaneous and subcutaneous tissues themselves.

\section{HISTORICAL MILESTONES}

Reconstructive rhinoplasty is an ancient art. Long before 800 BC, when Susruta ${ }^{4}$ wrote of the procedure, a low-caste sect of potters in ancient India were using the forehead flap to reconstruct the absent nose. ${ }^{2}$ Ancient Egyptians were practicing the art at least seven centuries earlier, ${ }^{2}$ but the technique came to be known as the Indian rhinoplasty (Fig. 2). ${ }^{5,14}$

Twenty-three hundred years after Susruta, the Indian rhinoplasty arrived in Europe. In the 15th and 16th centuries, the Brancas and Tagliacozzi utilized the forehead flap and then invented the delayed arm flap, developing what is today known as the Italian method (Fig. 3). 2,14 Condemned by the Church for 'interfering with the handiwork of God', Tagliacozzi's teachings died with him.

During the 17th and 18th centuries, flap reconstruction of the nose fell out of favor, but was brought back to Europe from India by the British in the late 18th century. ${ }^{2}$ The first European case of Indian rhinoplasty in over 200 years was carried out in 1814 by Mr John Carpue, an English surgeon (Fig. 4). ${ }^{2-6}$ He was familiar with the writings of Tagliacozzi, and had read an account of an Indian rhinoplasty reported in the Gentlemen's Magazine, October, 1794 (taken from the Madras Gazette, 1793). ${ }^{5}$ Numerous cases were recorded between 1814 and 1830, in England and on the continent. ${ }^{6,7}$ Up to this time, all of these surgeries were, of course, carried out without anesthesia.

By the early 1800's, the Indian rhinoplasty had reached North America. In 1832, Dr Gurdon Buck of New York

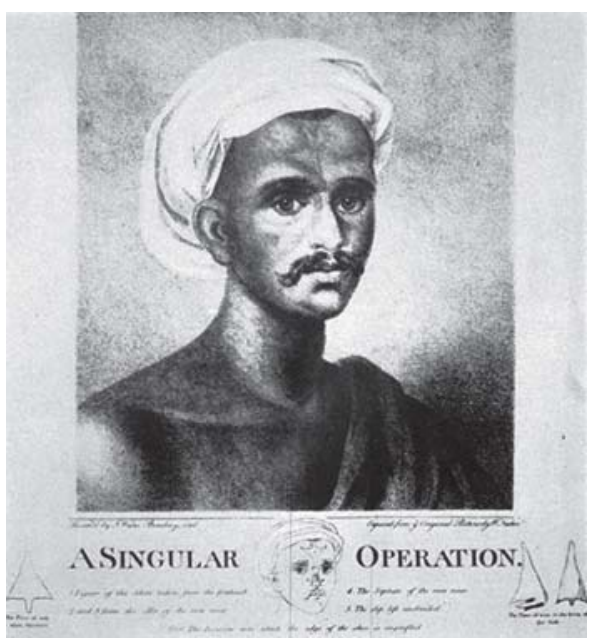

Fig. 2: Circa 800 BC: Susruta recorded Indian forehead flap rhinoplasty ${ }^{5,14}$

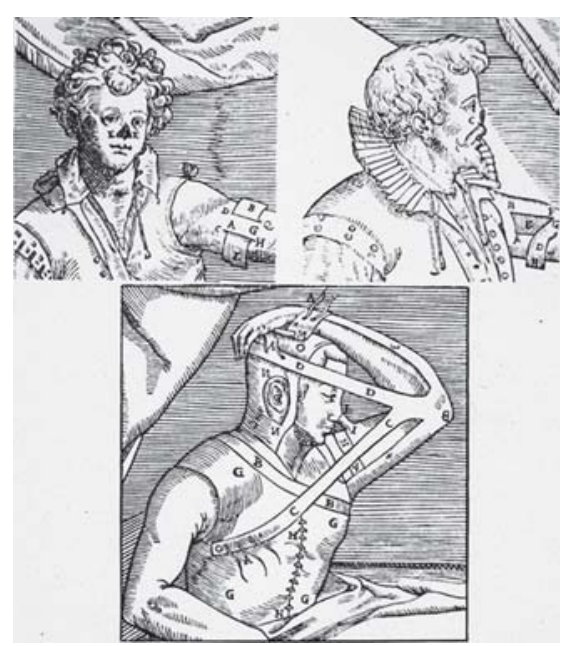

Fig. 3: Italian delayed arm flap of Tagliacozzi, $1597^{2,14}$

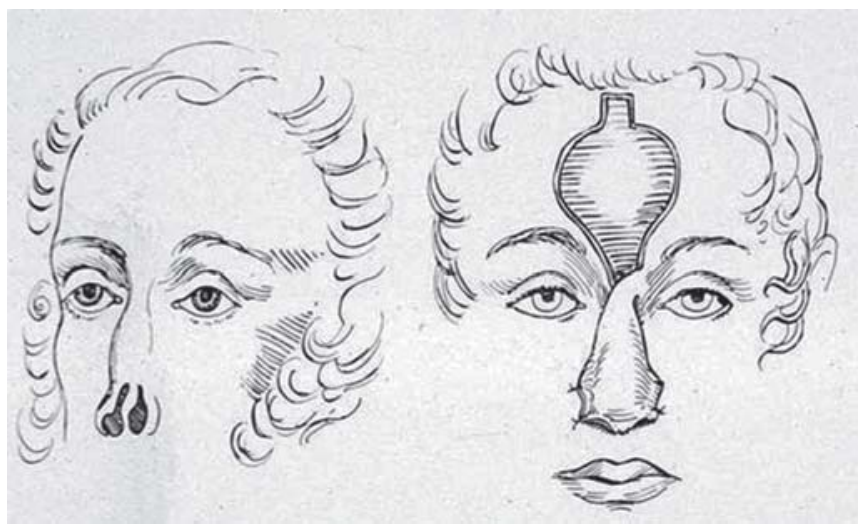

Fig. 4: Mr John Carpue reintroduced Indian forehead flap in England, $1814^{6}$

reported a case on which he carried out five operations on a male patient to reconstruct his missing right maxilla and sidewall of the nose, utilizing a forehead flap (Figs 5A to D). ${ }^{3}$ Mercifully, it was now possible to carry out this type of surgery under ether anesthesia. (Dr Buck, incidentally, was credited in 1846 with the first interosseous wiring of a fractured mandible).

As can be expected, numerous refinements on the basic Indian and Italian flaps have taken place in the past century and a half, paralleling the development of modern anesthesia. These are too numerous to detail here. Notable among these refinements, however, are the scalping flap ${ }^{8}$ of Dr John Converse of New York, in 1942; and the retroauricular-temporal flap ${ }^{9}$ developed by Dr Hiroshi Washio of Tokyo, first published in 1969.

The history of cosmetic and corrective rhinoplasty, as opposed to reconstructive rhinoplasty, dates back only to the mid-1800's. It was Dieffenbach, ${ }^{10}$ in 1845 , who is generally credited with having carried out the first reduction rhinoplasty. He treated a rhinophyma by means of a stellate external incision (Fig. 6). ${ }^{10}$ 

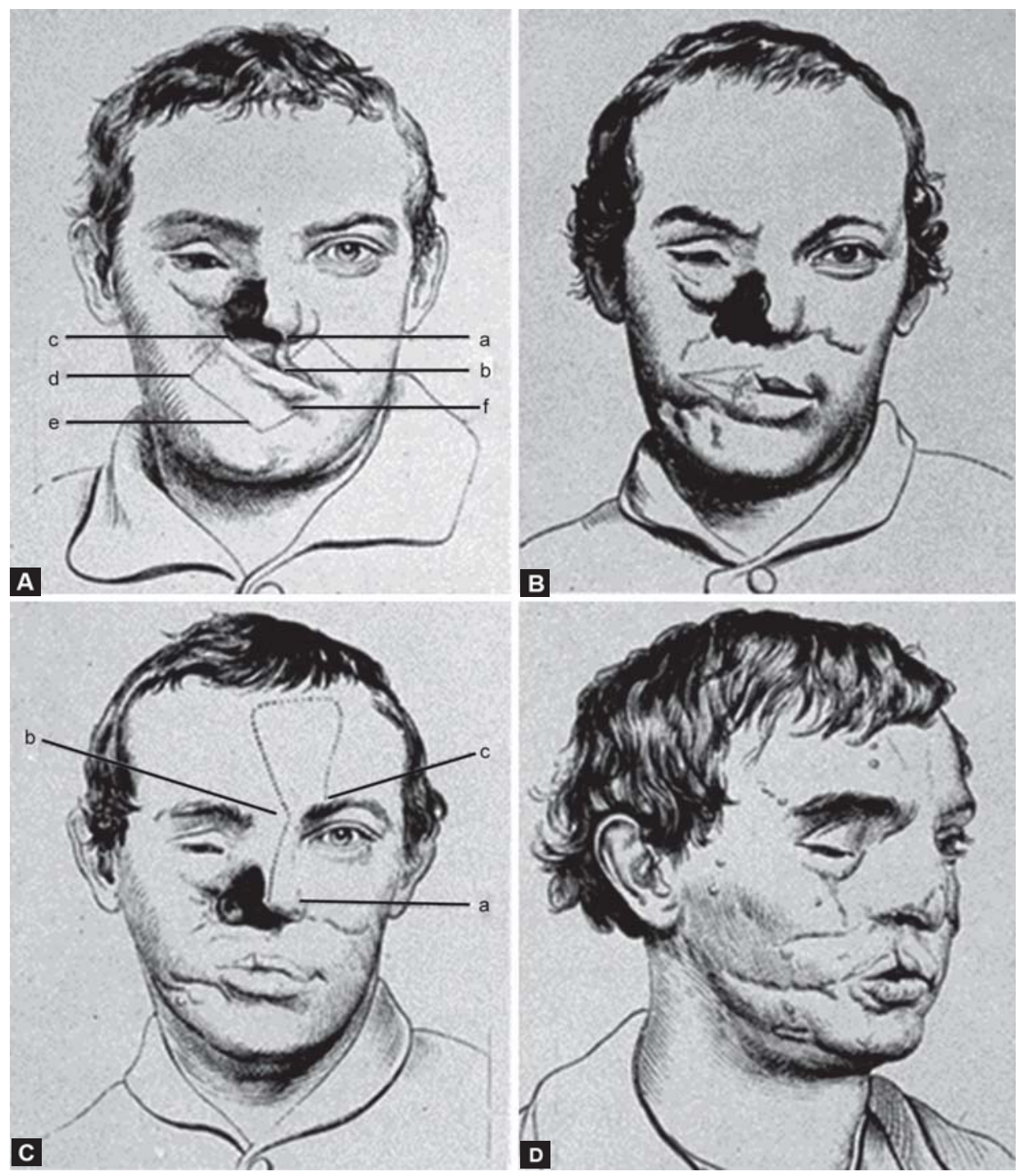

Figs 5A to D: Dr Gurdon Buck reported Indian forehead flap in USA, $1832^{3}$
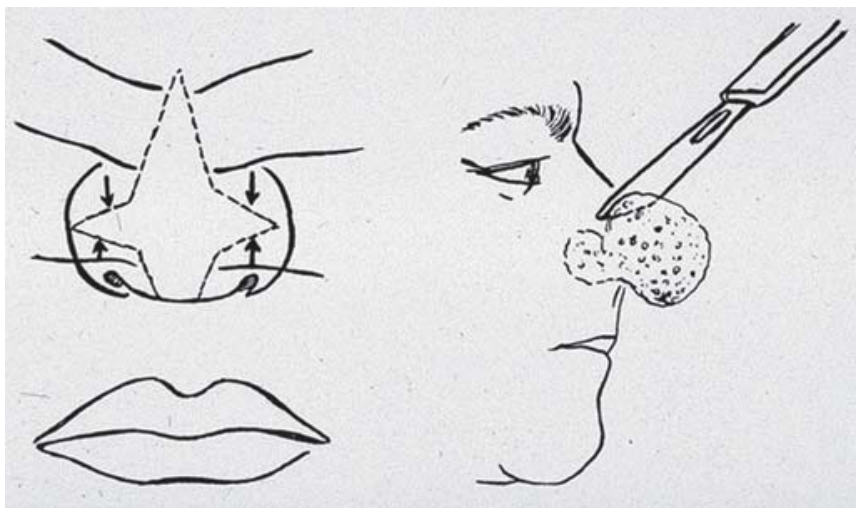

Fig. 6: Dr JF Dieffenbach, first reduction rhinoplasty, $1845^{10}$

The first rhinoplasty by means of intranasal incisions was carried out in 1887 by Dr John Roe, ${ }^{11}$ an Otolaryngologist in Rochester, New York. In February of that year, he read a paper before the Medical Society of New York, describing correction of a 'Pug-Nose' deformity via an endonasal approach. ${ }^{12}$ He presented a second paper to the same society in 1891, entitled 'Correction of angular

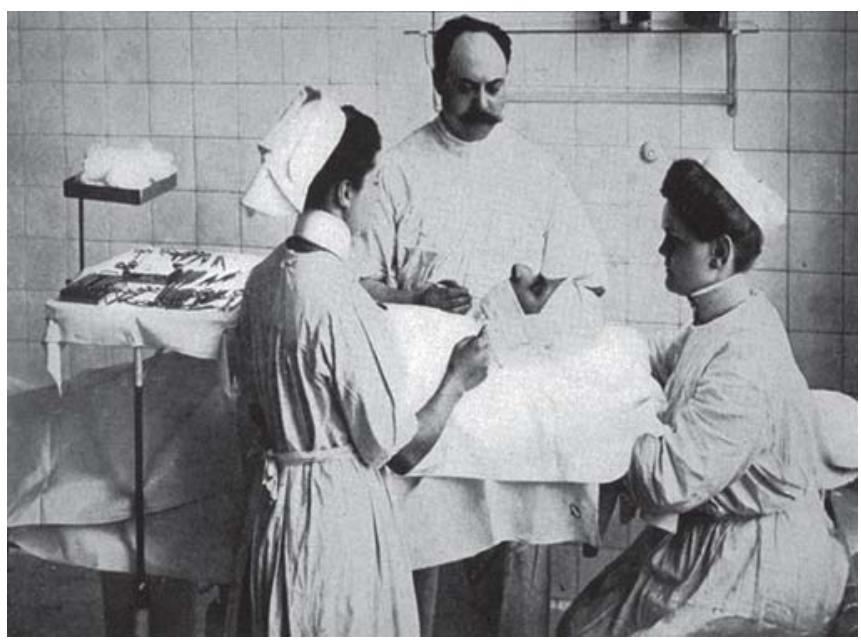

Fig. 7: Dr Jacques Joseph, pioneer of cosmetic and corrective nasal surgery, $1898^{5}$

beformities of the nose by a subcutaneous operation'. Besides describing strict antiseptic precautions and the use of iodoform powder blown over the wound to prevent infection, this second paper is remarkable for describing 
the use of cocaine for topical anesthesia, and for the injection of cocaine '... under the skin with a hypodermic syringe....' ${ }^{11}$

Though Dr Jacques Joseph reported his first case of rhinoplasty in 1898, 11 years after Roe's first publication, Joseph is generally acknowledged as the father of modern corrective rhinoplasty because of his extensive writings ${ }^{5,13,14}$ on this subject in the early 20th century, in Berlin (Fig. 7). ${ }^{5}$ Interestingly, his first case was carried out by means of external nasal incisions through tip and dorsum. His classic endonasal techniques were evolved later, and were probably based on the earlier writings of John Roe. To his credit, Joseph mentions these earlier reports in his first article on rhinoplasty, ${ }^{15}$ stating '...we found the mention of a few endonasal hump removals by Dr Row...' Dr Gustave Aufricht ${ }^{16}$ and Dr J Safian ${ }^{17}$ brought Joseph's techniques to the United States in the early 1900's, and themselves made significant contributions to the art of endonasal rhinoplasty surgery.

In 1899, Dr Friedrich von Mangoldt ${ }^{18}$ was the first surgeon to use autogenous rib cartilage, implanted via glabellar and nasolabial fold incisions to repair a saddle nose deformity. Among Joseph's noteworthy contributions, he reported use of part of one ala to repair the other ${ }^{19}$ in

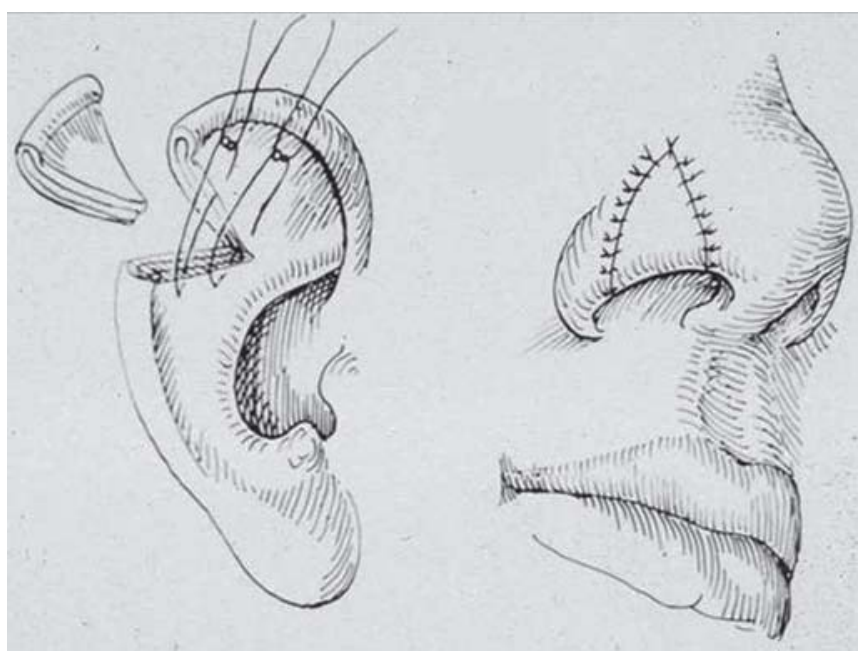

Fig. 8: Dr F Koenig, composite grafts from ear to nose, $1914^{6}$

1912, in effect the first use of a composite graft in nasal reconstruction. In 1914, Dr F Koenig reported his series of composite grafts to the nose, from the upper ear, ${ }^{20}$ while Dr A Limberg reported a similar and more successful series of cases $^{21}$ in 1935 (Fig. 8). ${ }^{6}$

Meanwhile, Dr Aurel Rethi, of Budapest, reported his transcolumellar incision and external approach to the nasal tip, in $1921 .^{22}$ This innovative technique was the beginning

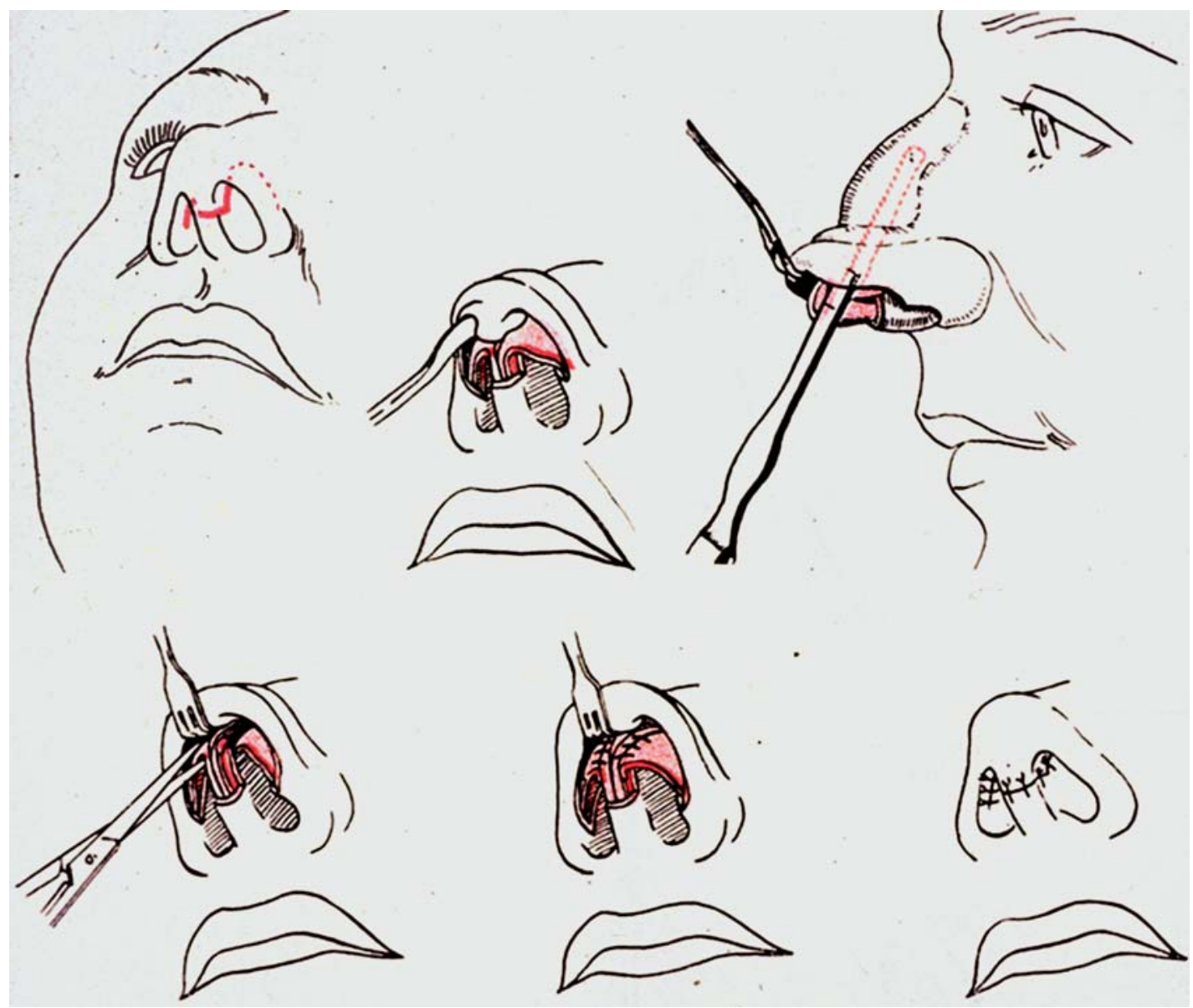

Fig. 9: Dr Aurel Rethi created the external approach open rhinoplasty technique, $1921^{2}$ 
of what is today known as the external approach or 'open' rhinoplasty (Fig. 9). ${ }^{2}$ Like many new and 'radical' ideas, his technique was initially not readily accepted, even with further writings in $1934,{ }^{22}$ perhaps because he initially confined this approach to the nasal tip. It was in 1956 that Dr A Sercer, in Zagreb, reported the use of Rethi's approach to expose the entire nasal infrastructure, ${ }^{23}$ the same year that Rethi himself reported using his approach in the repair of saddle nose deformity. ${ }^{24}$ The external approach to rhinoplasty gained wider acceptance in Europe during the next decade, but was slower to catch on in North America. Dr Samuel Fomon, of New York, mentioned and illustrated Rethi's technique in his influential text ${ }^{2}$ in 1939 describing it as the best of the external incisions, to which he remained generally opposed. (Ironically, a study of the text describing the illustration reveals an incomplete understanding of the technique). He mentions it again in his second text ${ }^{11}$ published in 1960, but mainly to state that he abandoned the approach for use in dorsal augmentation.

Several other 'new' developments took place in the 1940' and 1950's. Among these was the appearance, in the English literature, of the use of the composite ear graft in nasal reconstruction. Following the leads of Koenig and Limberg, Dr Harold Gillies, in England, described the use of a composite conchal graft in reconstruction of the ala ${ }^{25}$ in 1943; and Dr's James Brown and B Cannon reported use of similar grafts ${ }^{26}$ in the United States in 1946. In 1953, Dr Irving Goldman published his techniques for narrowing the nasal tip and increasing tip projection, ${ }^{27}$ a major advance in the management of the thick-skinned nose.

The pace of introduction of new ideas in cosmetic and corrective rhinoplasty quickened during the 1960's and 1970's. Dr Jack Anderson described his cartilage-splitting incision $^{28}$ in 1966, minimizing the number of intranasal incisions. He also emphasized the importance of shortening the lateral crura, rather than the septum, in effecting shortening of the nasal tip and nose overall. Shortly thereafter, in 1966, Dr L Padovan (also of Zagreb) published further on the external approach technique. ${ }^{29}$ Like Sercer, his cases numbered in the hundreds. Padovan reintroduced the concept to North America in 1970, at the 1st International Symposium on Plastic and Reconstructive Surgery, in New York; and Dr Wilfred Goodman of Toronto, Canada, helped popularize it through papers ${ }^{30,31}$ published in 1973 and 1974.
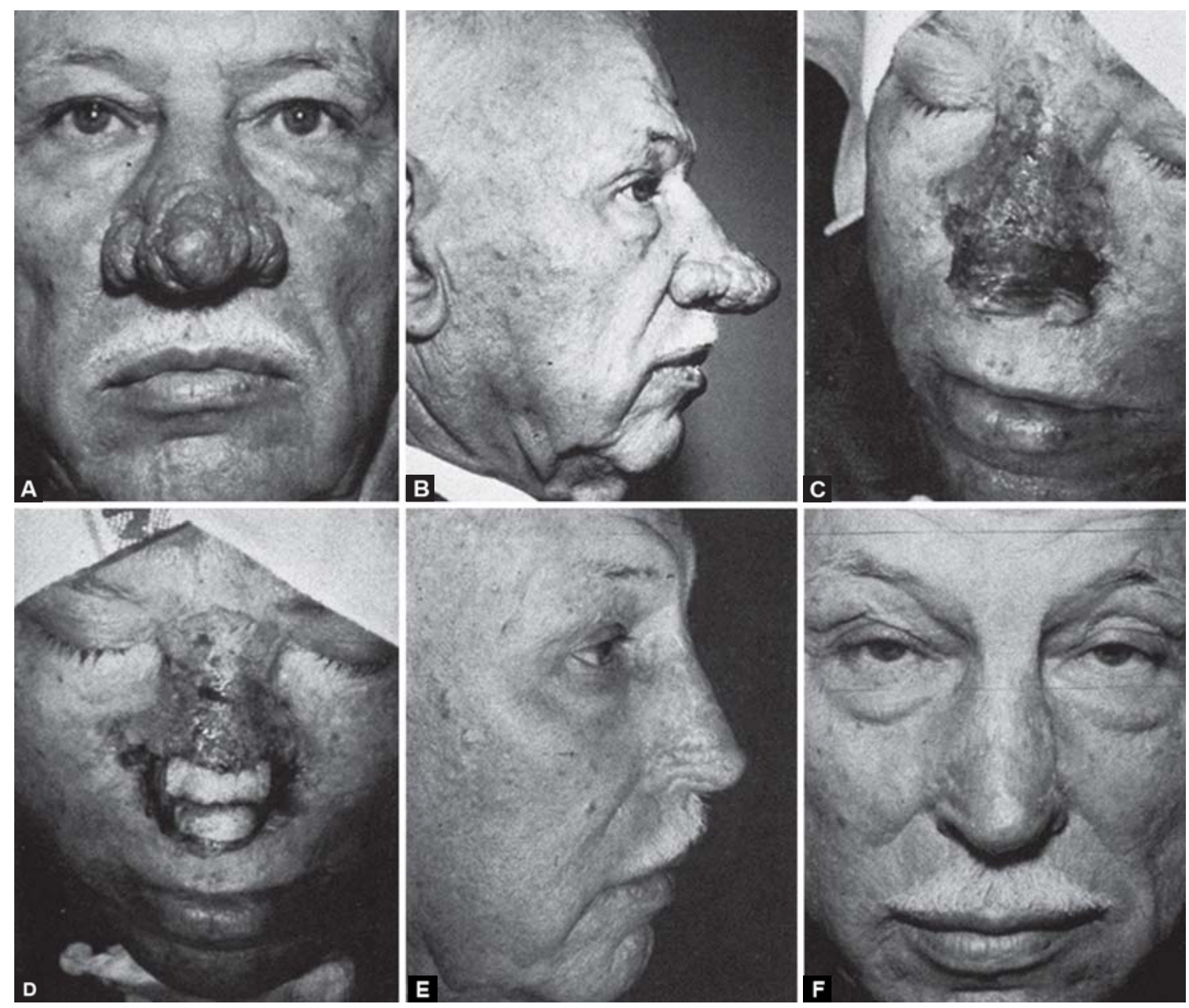

Figs 10A to F: Dr Bromley Freeman—direct cutaneous incisions and skin grafting for rhinophyma rhinoplasty, $1970^{6,32}$ 
In 1970, another 'new' concept was reintroduced by $\mathrm{Dr}$ Bromley Freeman, in Texas: like Dieffenbach before him, he reported on management of rhinophyma by means of direct excision of involved skin and subcutaneous tissues, combined with surgical planing (Figs $10 \mathrm{~A}$ to F). ${ }^{6,32}$ Meanwhile, it was Dr Reed Dingman from Michigan and Dr Claus Walter from Germany who in 1968 again presented the use of composite ear grafts, this time to reconstruct the skeletal infrastructure of the nose. ${ }^{33}$ During the 1970 's, the use of free grafts in nasal reconstruction was further amplified by Walter ${ }^{34}$ in both the English and German literature.

On the cosmetic side of the scale, Dr Jack Sheen of Los Angeles reintroduced the concept of inserting a septal cartilage autograft ${ }^{35}$ into the nasal tip region in 1975, to achieve more nasal tip projection. His placement of the autograft was anterior to the domes of the tip cartilages, rather than overlying the domes, as described by Fomon ${ }^{11}$ in 1960.

During the past two decades, many minor but significant advances have been described, pertaining to refinements in conventional rhinoplasty technique. Many of these refinements have dealt with methods of achieving or maintaining tip projection, with the use of allograft materials, and with the management and prevention of secondary deformities. ${ }^{36-56}$ During the same period, the value of the external approach in rhinoplasty has gained wider acceptance, as exemplified in 1986 by the publication of Anderson's and Ries' monograph on rhinoplasty for the American Academy of Facial Plastic and Reconstructive Surgery, emphasizing the external approach. ${ }^{41}$
Through a review of the history of rhinoplasty, it can thus be seen that the development of the external approach or 'open' rhinoplasty has paralleled the modern development of conventional or 'closed' methods, since the latter half of 19th century. Neither method, however, is suited to dealing with the problems posed by the rigid skin nose.

Part II of this paper ${ }^{58}$ will hopefully draw attention to the role that dorsal cutaneous incisions and excisions can play in the management of the spectrum of nasal deformities, be they cosmetic, hereditary, traumatic or iatrogenic in origin.

\section{CONCLUSION}

Through this brief review of key historical milestones in the history of rhinoplasty, it can be seen that the development of the external approach or 'open’ rhinoplasty has paralleled the modern development of conventional or 'closed' methods since the latter half of the 19th century. Neither method, however, is suited to dealing with the problems posed by the rigid skin nose.

The second part of this paper is entitled 'Dorsal Approach Rhinoplasty_-Part II: A Radical Approach to the Rigid Skin Nose. ${ }^{58}$ In Part II, the author introduces his novel 'eagle wing' incision technique of dorsal approach rhinoplasty, which he designed to overcome the challenges of the rigid skin nose. Part II will also draw attention to the role that dorsal cutaneous incisions and excisions can play in the management of the entire spectrum of nasal deformities.

\section{Part II: A Radical Approach to the Rigid Skin Nose}

\section{ABSTRACT}

Direct dorsal excision of skin and subcutaneous tissue is employed in rhinoplasty cases characterized by thick rigid skin to achieve satisfactory esthetic results, in which attempted repair by more conventional means would most likely frustrate both surgeon and patient.

The dorsal approach facilitates debulking of the nose by means of excision of nasal subcutaneous musculoaponeurotic system (SMAS) and thickened subcutaneous tissues. More importantly, direct dorsal excision permits direct reduction in skin surface area and volume without which repair attempts would most likely fail in spite of alteration of the nasal skeletal framework, because of the rigidity of the skin itself. Exposure via the dorsal 'eagle wing' incisions is equal or superior to the transcolumellar approach. Intraoperative dermabrasion and proper positioning of the incisions are important in minimizing the resultant dorsal cutaneous scar.

Two cases are described: Secondary repair of a scarred nose in an older male previously treated elsewhere for rhinophyma; and esthetic correction in a young male, of a broad nose affected by early acne rosacea. Preoperative, intraoperative and postoperative photographs and diagrams are presented, to help illustrate the surgical techniques and results achieved. The subject of dorsal nasal incisions is reviewed in the literature. The author feels the technique presented provides a valuable surgical alternative for those cases who might otherwise be advised 'nothing further can be done', because of their scarred or rigid nasal skin.

Keywords: Dorsal approach rhinoplasty, Eagle wing incision, Rigid skin nose, External approach rhinoplasty, Historical milestones.

\section{INTRODUCTION}

Review of the history of rhinoplasty, as presented in 'Dorsal Approach Rhinoplasty_Part I: Historical Milestones in Rhinoplasty, ${ }^{57}$ reveals that the development of the external approach or 'open' rhinoplasty has paralleled the modern development of conventional or 'closed' methods, since the latter half of the 19th century. 
There remains a group of 'problem noses', however, in which even the transcolumellar external approach will prove inadequate, as neither method is capable of dealing with the challenges posed by the rigid skin nose. These noses are characterized by bulky and/or rigid skin, due to heredity, scarring or disease of the cutaneous and subcutaneous tissues themselves.

This paper, Part II, will draw attention to the role that dorsal cutaneous incisions and excisions can play in the management of the entire spectrum of nasal deformities, be they cosmetic, traumatic or iatrogenic in origin. To this end, the author presents his novel 'Eagle Wing' incision technique, and the procedure he has named the 'Dorsal Approach’ (as opposed to ‘external approach’) rhinoplasty.

\section{INDICATIONS}

The indications for external approach rhinoplasty have been elegantly summarized by Dr Wilfred Goodman, ${ }^{30}$ as listed in Table 1. To these, some surgeons would add: 'Any cosmetic nasal asymmetries.' I personally prefer to reserve this approach for the more challenging nasal deformities in which, however, the skin is more-or-less normal.

The indications for dorsal approach rhinoplasty are somewhat different, having first of all to do with the condition of the skin and subcutaneous tissues overlying the skeletal infrastructure, as shown in Table 2. If rigidity, thickness or scarring of these tissues is likely to prevent them from conforming to the surgically-altered skeletal framework, consideration should be given to direct excision of the skin, subcutaneous tissues and nasal subcutaneous musculoaponeurotic system (SMAS), to reduce skin volume and surface area directly.

In rhinophyma, there is often an associated hypertrophy and/or drooping of the nasal tip cartilages and skeletal elements. Dorsal approach rhinoplasty technique permits simultaneous correction of both the soft tissue and skeletal elements, in managing this difficult disfiguring problem.

The same applies equally well to the more purelycosmetic problems posed by reduction rhinoplasty of the

Table 1: Goodman classification ${ }^{30}$ of indications for the external approach rhinoplasty

1. Congenital deformities of the nose.

2. Major nasal septal deformities.

3. Large hump nose with cartilaginous deformities.

4. Major augmentation procedures accompanied by cartilaginous deformities.

5. Excision of dermoid cysts or other pathology.

6. Correction of the bifid tip.

7. Excision of subcutaneous scar tissue.

8. Reoperations with major deformities.
Table 2: Dubeta classification of indications for the dorsal approach rhinoplasty

A. Reduction rhinoplasty-in noses with:

1. Scarred or rigid skin

- Surgical or traumatic causes

- Acne vulgaris scarring

2. Thick skin and subcutaneous tissues

- Subcutaneous fibrosis

- Acne rosacea, cystic

3 Large or broad nose with bulky tip - Hereditary

B. Rhinophyma repair:

1. Primary

2. Secondary

C. Nasal deformity repair:

1. Severe short nose deformity

2. Severe nasal deformity

- Primary trauma repair

- Secondary/delayed repair

large or broad nose with rigid, thick skin of the tip and supratip regions. Skin thickening in these individuals may be purely hereditary, or due to the sebaceous gland hypertrophy of acne rosacea.

Finally, the severe short-nose deformity and severe nasal deformities in general can be approached by a variety of dorsal nasal incisions, not only the 'eagle wing' or 'chevron' incision used to manage the two cases described herein.

\section{PREOPERATIVE MANAGEMENT}

Patients who are candidates for dorsal approach rhinoplasty should have bacterial culture and sensitivity studies of swabs taken from the nasal vestibules, and in the case of acne scarring, from any active pustular acne lesions. They should be treated with appropriate prophylactic antibiotics, and should ideally have preoperative dermatologic assessment and management as well.

Preoperative planning and photographic analysis of the face and nose are essential elements in ensuring success of the procedure. This can be done by computer-assisted imaging and analysis, though I personally prefer the 'handson' experience gained by drawing the corrected facial and nasal profile on tracing paper or on the back of standardized two-thirds life-size $5 \times 7$ inch black and white or color photographs, working on a back-illuminated drawing table. The image so produced should realistically represent the results to be expected from this type of surgery and not merely reflect the surgeon's and the patient's esthetic ideal. Pre- and postoperative photographs are shown, of other patients with similar problems. Whenever possible, and particularly if requested, arrangements are made preoperatively to have the rhinoplasty candidate meet with an individual who has already had a similar procedure, to assess his or her experiences, preoperative findings and postoperative results. 
Because the surgery involves the creation of a dorsal nasal scar, albeit a well-camouflaged or hopefully 'invisible' one, these patients require more than the usual amount of preoperative counseling and reassurance. Informed consent must be given, and the risks of the procedure weighed carefully against the potential benefits. Patient selection is therefore extremely important, and this type of surgery would best be avoided if a surgical procedure with lessconspiciously located scars can be anticipated to give a satisfactory result, in the particular individual under consideration.

\section{Technique of Dorsal Approach Rhinoplasty}

The technique described pertains to cosmetic or reduction rhinoplasty in the thick skin nose.

The key to the success of this surgery, from the esthetic point of view, is the design and placement of the dorsal cutaneous incisions. Second in importance is the use of intraoperative dermabrasion to maximize epidermal blending, and minimize the resultant dorsal cutaneous scar.

Caution should be exercised, however, in the use of dermabrasion in darker-skinned individuals (Fitzpatrick type IV or higher) because of the risk of post-inflammatory hyperpigmentation. Similarly, they should be advised that ANY dorsal nasal incision scar in of itself may heal as a visible brownish line in the nasal supratip region, with or without dermabrasion. In this sense, the visibility or lack thereof of the post-surgical scar is always a 'trade-off', to be weighed against the visibility of the pre-existing deformity.

The surgery is carried out under general anesthesia, or local anesthesia with sedation. In either case, the subcutaneous tissues are infiltrated with lidocaine 1 or $2 \%$ with $1: 100,000$ or $1: 200,000$ adrenaline, to assist in hemostasis.

To achieve debulking and narrowing of the tip and supratip, direct excision of skin, subcutaneous tissues and nasal SMAS will be carried out. As is appropriate for the particular features which have to be corrected in the nose in question, an 'eagle wing' incision is marked out on the tip dorsum and supratip skin, encompassing the skin strip to be excised (Fig. 1A). The center of the incision forms a shallow curved ' $\mathrm{V}$ ' at the cephalic margins of the reshaped lateral crura. The inferior and superior incision margins are similarly marked out, but the ' $\mathrm{V}$ ' of the superior margin is somewhat shallower. The vertical (sagittal) width of the skin strip to be excised corresponds to the amount of tip elevation required and/or the amount of dorsal and tip narrowing desired.

The lateral 'wings' of the eagle wing incision curve cephalically as well as dorsally, i.e. 'up and away' from the midline (Fig. 1B). Curving the incision away from the alar lobules avoids segregating the lobules from the supratip sidewalls (as would occur with a standard gullwing incision curving down into the alar grooves), and extends the amount of dorsal exposure possible. The lateral wings of the incision can be extended a considerable distance up the nasal sidewalls, if necessary, while still maintaining excellent length to width ratios of the resultant superior hinge flap of dorsal nasal skin.

At this point, the shape and position of the incision is conceptualized, or a template can be made of paper or cloth. The skin of the nose is then dermabraded, removing a layer
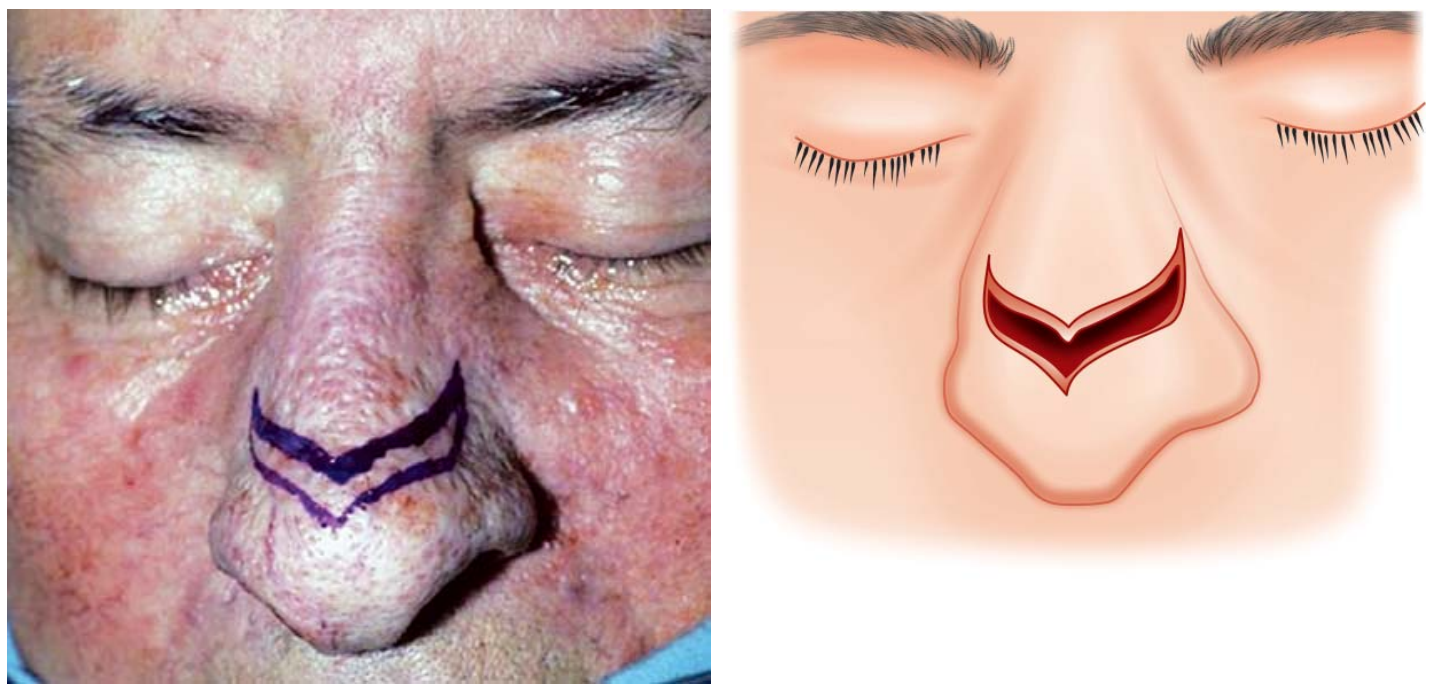

Fig. 1A: Skin marking for dorsal 'Eagle Wing' incisions: Planned skin and sub-Q excision (refer to text) 


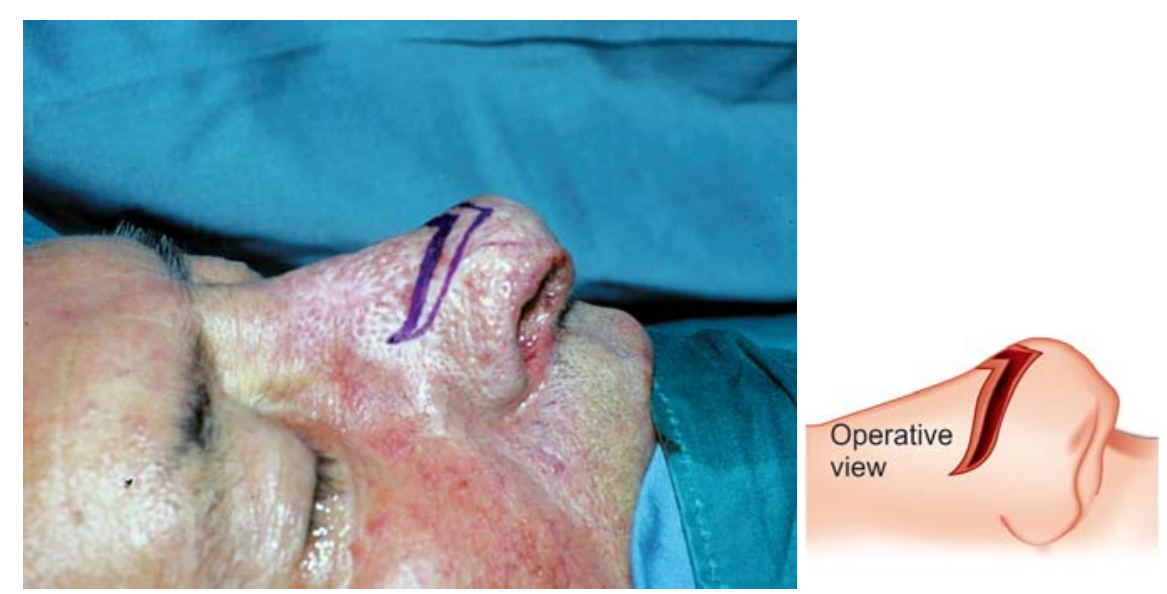

Fig. 1B: Skin markings for dorsal 'Eagle Wing' incisions—operative view (refer to text)
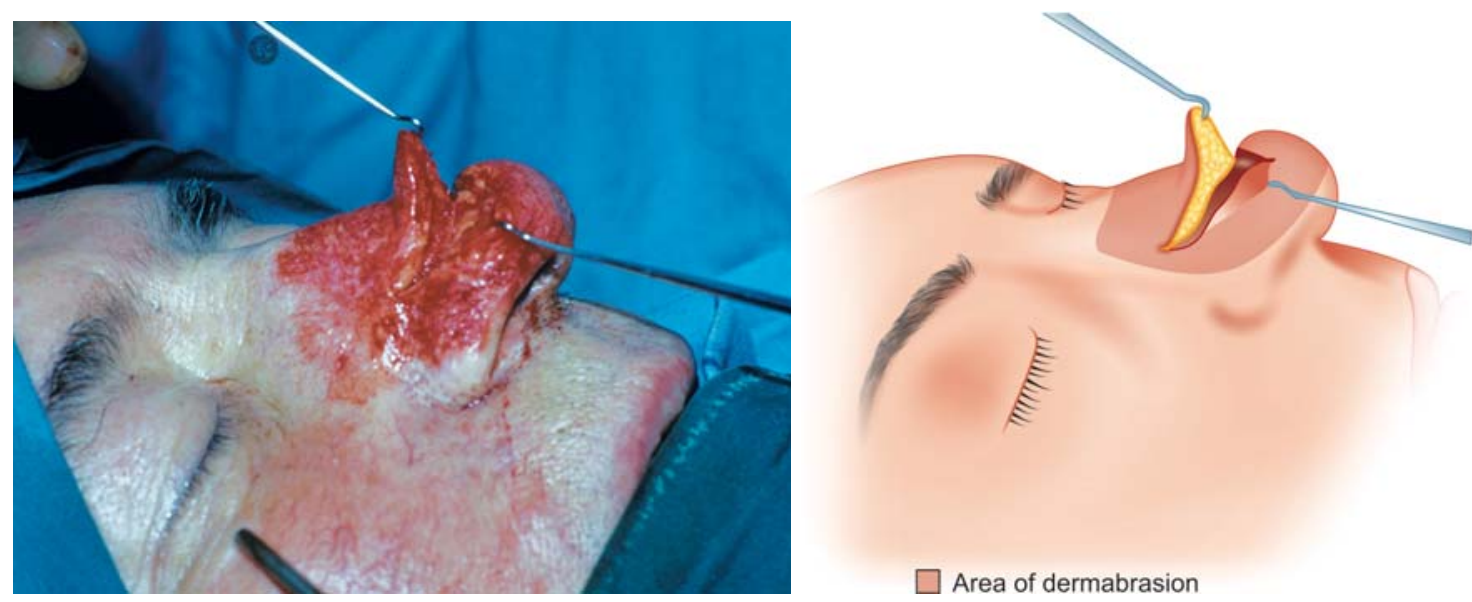

Fig. 2: Elevation of dorsal hinge flap—dorsal approach technique

of epidermis to the depth of erythema and slight vascular oozing. This erases the markings for the eagle wing incision, as dermabrasion is carried out for at least $5 \mathrm{~mm}$ cephalic and caudal to the superior and inferior incision margins previously delineated.

The inferior or caudal margin of the incision is then made with a number 15 scalpel blade and curved upward and outward from the ' $\mathrm{V}$ ' at the center, sweeping away from the alar lobules at the wing 'tips'. While the superior incision margin can be lightly scored out onto the dermabraded skin of the superior hinge flap, it should be emphasized that the marked out strip of skin is not excised at this stage. Rather, the sagittal width of the skin strip to be resected is determined later, just prior to closure. This is done through redraping the superior flap over the inferior incision margin, after suitable reshaping and repositioning of the tip cartilages and other skeletal elements has been achieved.

Elevation of the superior 'hinge' flap (Fig. 2) is carried out in either the immediate subdermal plane, just superficial to the SMAS of the nose, or in the plane immediately superficial to perichondrium and periosteum of the nasal dorsum, depending on the condition of the skin and subcutaneous tissues. In the latter instance, the transverse SMAS incision (also of eagle wing configuration), is made 2 or $3 \mathrm{~mm}$ cephalic to the cutaneous incision, so that the wound closure can be carried out in staggered layers if only mild debulking of the supratip region is required. The SMAS layer and excess sub-Q tissues are dissected away from the cutaneous tissues of the hinge flap, using sharp and spreading scissor dissection (Fig. 3). This step is carried out only if a suitable plane of dissection can be found, as particular care must be taken to leave a subdermal layer attached to dermis, sufficiently thick to nourish the cutaneous layers. In noses affected by acne rosacea, or in secondary rhinophyma cases, the remarkable dilation of the sebaceous glands will be seen and the cut skin margins may be noted to exude a whitish 'milk' of sebaceous secretion from their edges. The lateral crura of the lower lateral cartilages can be fully exposed by elevation of the tip skin and sub-Q tissues caudal to the eagle wing incision. If 

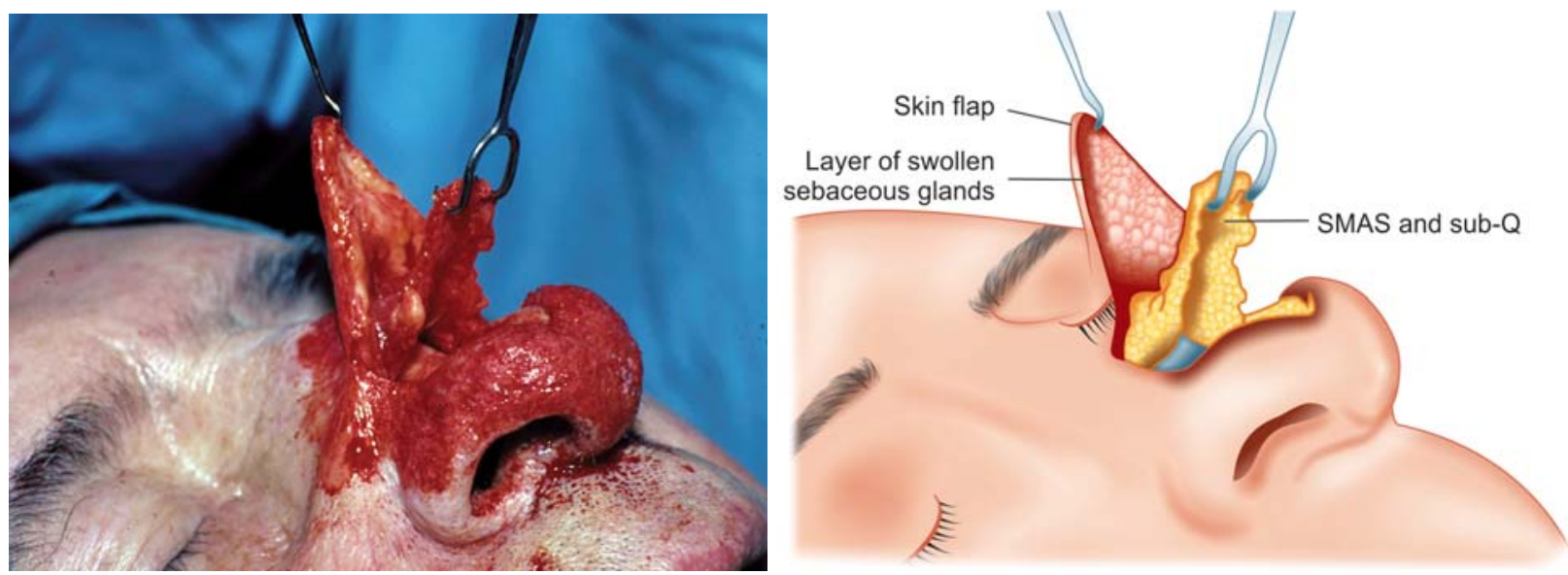

Fig. 3: Elevation of skin and SMAS flaps. Note: Swollen sebaceous glands in skin flap
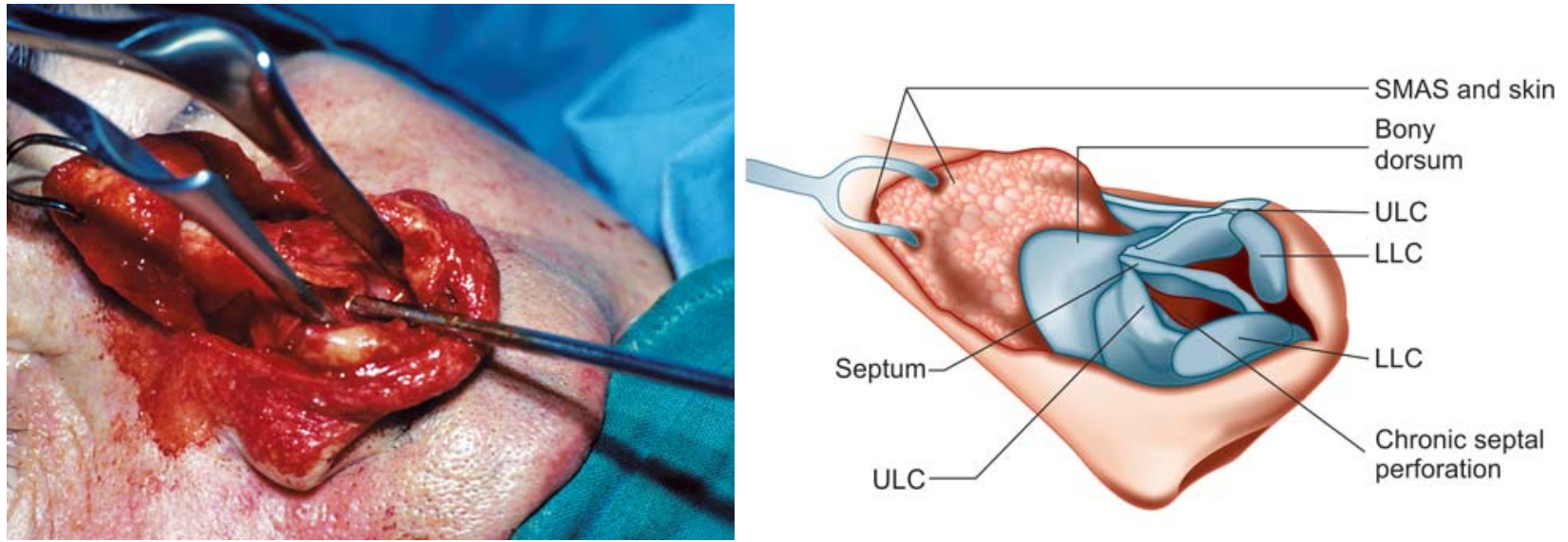

Fig. 4: Full dorsal, septal and tip exposure is provided with dorsal approach technique

necessary, dissection can be carried well down into the columella, caudal to or between the medial crura. As with external approach rhinoplasty, the membranous septum can be bivalved to expose the caudal margin of the quadrangular cartilage, down to at least the level of the nasal spine (Fig. 4).

Such adjustments to the bony and cartilaginous skeleton as are required can now be carried out under direct vision. If the nasal dorsum is opened, as with hump removal or straightening procedures, the nasal septum can be accessed submucosally and subperiosteally, in its entirety.

The SMAS layer is handled in one of two fashions, depending on the amount of debulking required. If the problem is a rigid, drooped tip with relatively-normal pliability of the supratip skin, the SMAS flap can be trimmed along its caudal margin at a level near to the caudal margin of the skin incision, once the tip has been adjusted to the desired operative position. Alternately, if greater debulking of tip, supratip and dorsum is required, the thickened SMAS and subcutaneous tissues may have to be resected entirely. In either case, defatting of the tip is usually indicated, excising fibrotic or hypertrophied sub-Q tissues and SMAS of the tip itself to permit better skin redraping over the reshaped tip cartilages.

Trimming of the superior hinge flap can now be carried out. This is achieved by overlapping the lower, caudal margin of the eagle wing incision with the hinge flap, using skin hooks for traction. With the nasal tip in the desired position and the nasolabial angle satisfactorily adjusted, the amount of skin overlap determines the width of the skin strip to be excised, and the position of the upper margin of the eagle wing incision. This process can be assisted by incising sagittal 'darts' along the overlapped superior skin flap margin, as far cephalically as the underlying (caudal) eagle wing incision. Then, the tips of the darts are joined together to create an upper incision margin and excise the intervening skin.

Or, if the previously-created template seems appropriate, the template can be applied along the free margin of the hinge flap once the skeletal elements have been adjusted and the SMAS layer and excess sub-Q tissues have been excised. The superior margin of the eagle wing incision is then made along the superior template margin, and the intervening strip of skin is excised. 

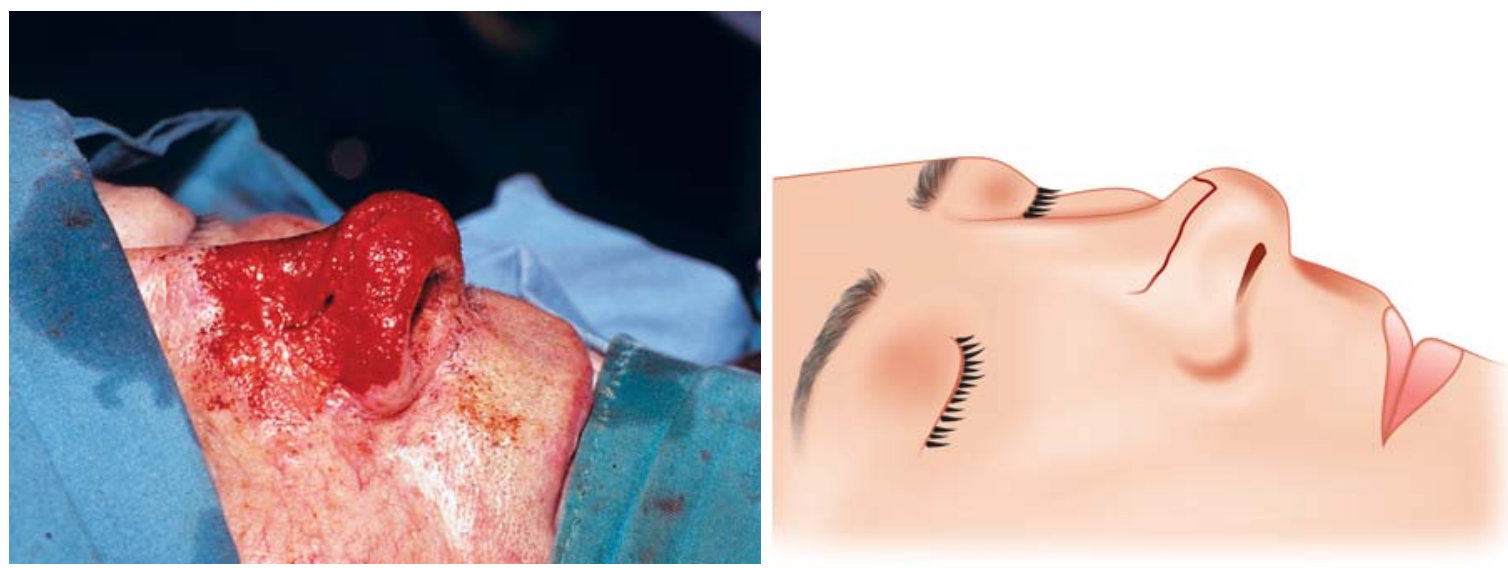

Fig. 5: Closure following tip repositioning, followed by skin and SMAS excisions. Note: Dermabraded skin to minimize scar visibility

The wound is then closed in layers. If dorsal SMAS and/ or sub-Q has been preserved, it can be reattached to the sub-Q or perichondrial tissues anterior and lateral to the anterior septal angle using a few tacking sutures of 5-0 chromic gut. Fine interrupted sutures of 6-0 nylon are then used to reapproximate the skin wound margins (Fig. 5). Slight further trimming of the superior and inferior skin margins may be carried out, as appropriate, at the time of closure. Correction of any columellar overhang can be carried out at this time, via separate columellar vestibular incisions.

Considerable judgment must be exercised regarding the use of alar base wedge resections, to narrow the base of the nose. If there is evidence of previous columellar surgery, this procedure should probably be deferred to another day, for fear of jeopardizing blood supply to the skin of the nasal tip. However, it is felt that the up-sweep of the eagle wing incision, away from the alar lobule and groove, helps to maintain the vascular supply of the inferior skin flap overlying the tip structures. This conversely reduces the risk of avascular necrosis of the tip skin if wedge resections of the alar lobules are carried out at the time of reduction rhinoplasty, but the condition of the regional skin must still be taken into careful consideration.

It should be mentioned that in primary rhinophyma surgery, subepidermal skin flaps are created by planing of the hypertrophic skin. ${ }^{32}$ Following this, reduction rhinoplasty can then proceed in the same manner described above. No further dermabrasion of the raw-surfaced subepidermal skin is necessary, except as required to smoothen out the planing margins circumferentially.

At the conclusion of the procedure, light packing of the nasal vestibules and fossae may be carried out if necessary using folded Telfa strips and Gelfoam coated with antibiotic ointment. A thin layer of the same ointment is spread over the dorsal incision and dermabraded skin, followed by application of a routine tape and plaster splint which is removed on the second to sixth postoperative day. Routine postoperative care is implemented. Nasal packing, if any, is removed 1 to 2 days following surgery. Prophylactic antistaphylococcal antibiotics, topically and orally, are maintained until re-epithelialization of the dermabraded skin is complete. Sutures are removed on the fifth to seventh postoperative day, depending of the condition of the dermabrasion eschar. The patient is then seen at regular intervals for routine follow-up care, not the least of which is reassurance that the initially reddish or violaceous dermabraded skin and dorsal scar will eventually fade to normal color. Caution should again be advised in recommending dermabrasion to darker skinned individuals, because of the risk of post-inflammatory hyperpigmentation.

\section{CASE REPORTS}

\section{Case 1}

A 21-year-old man presented with concerns about his large, broad nose and facial acne scarring as well as skin 'bumps' near the nasal tip. He was in the care of a dermatologist when first seen. The facial skin showed moderate generalized acne scarring. Preoperative assessment revealed him to have extremely thick nasal skin with large intracutaneous sebaceous cysts projecting above the surrounding skin surface (Fig. 6). It was judged impossible to achieve the nasal reduction and narrowing he desired, without direct excision of nasal skin. Furthermore, the unsightly supratip cysts could not have otherwise been removed. Facial dermabrasion and dorsal approach rhinoplasty were recommended.

Full face dermabrasion was carried out by the author, with satisfactory results, following which the patient returned for cosmetic dorsal approach rhinoplasty 5 months later. The nasal surgery was carried out under general 


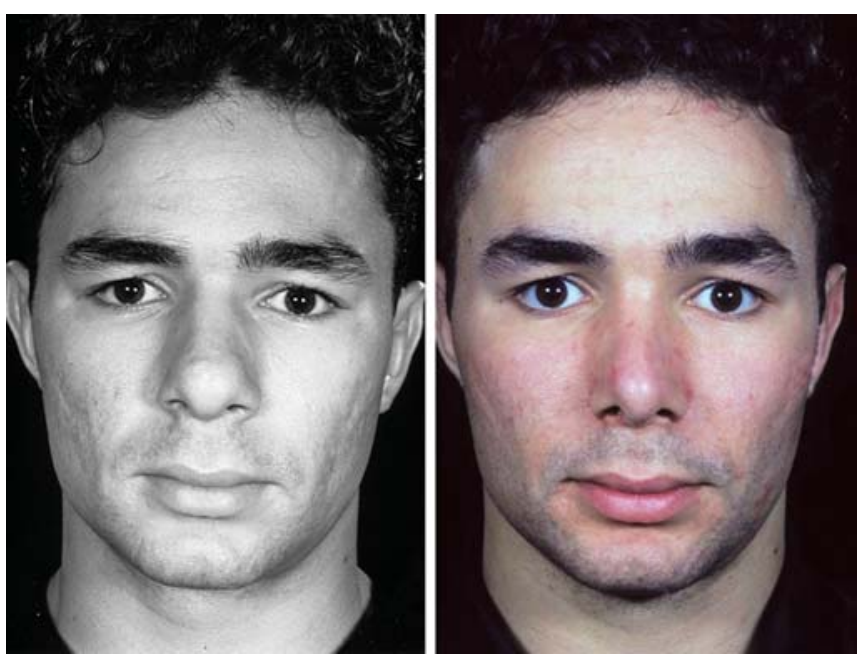

Fig. 6: Dorsal approach rhinoplasty, cosmetic. 21-year-old male with extremely thick nasal skin, broad nasal tip and large intracutaneous sebaceous cysts projecting above skin surface (cystic acne rosacea)

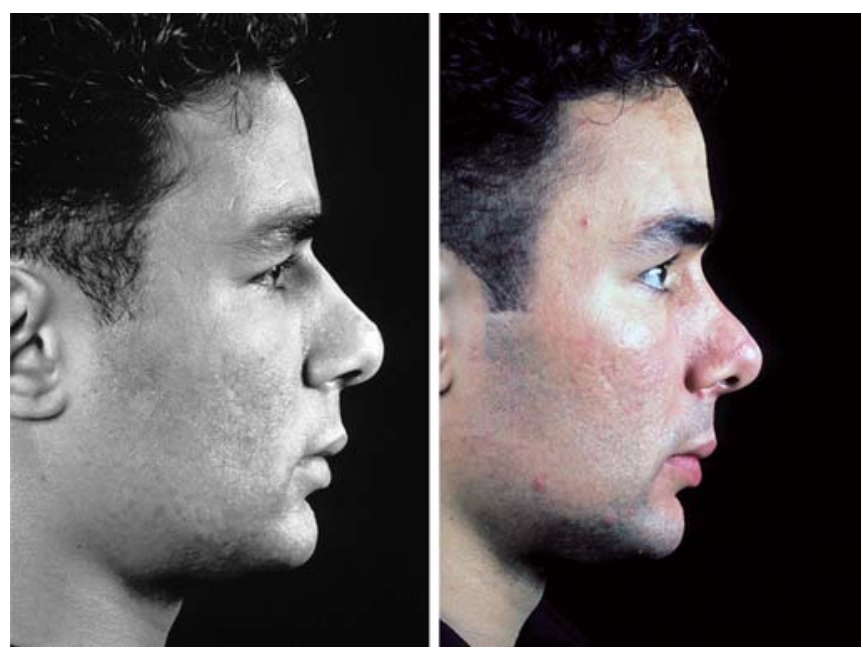

Fig. 7: Dorsal approach rhinoplasty, cosmetic. 21-year-old male, 9 months postoperative. Note: Development of new sebaceous cyst, just cephalic to minimally-visible chevron-shaped 'Eagle Wing' dorsal incision scar
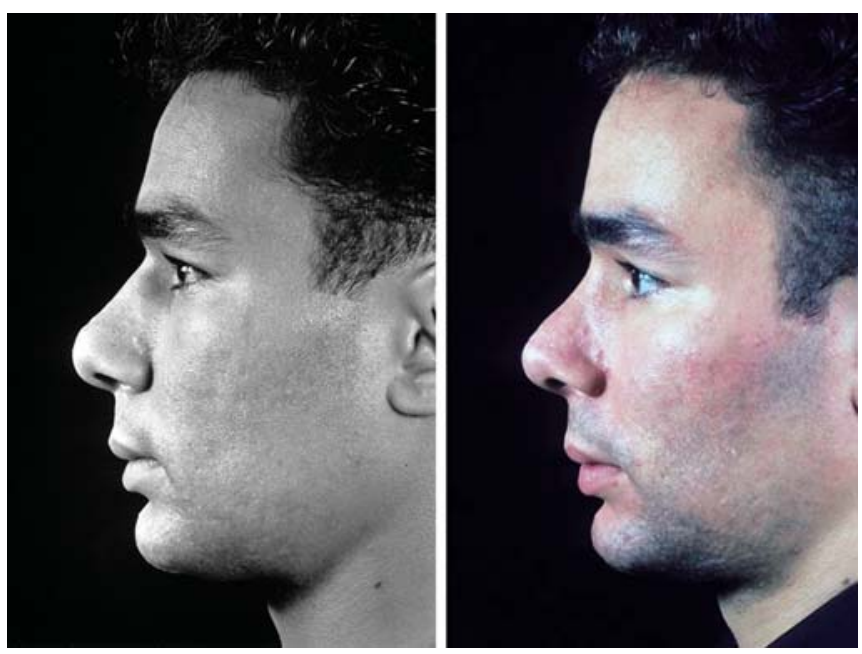

Fig. 8: Dorsal approach rhinoplasty, cosmetic. 21-year-old male, 9 months postoperative. Note: Minimally-visible chevron-shaped supratip 'Eagle Wing' dorsal incision scar

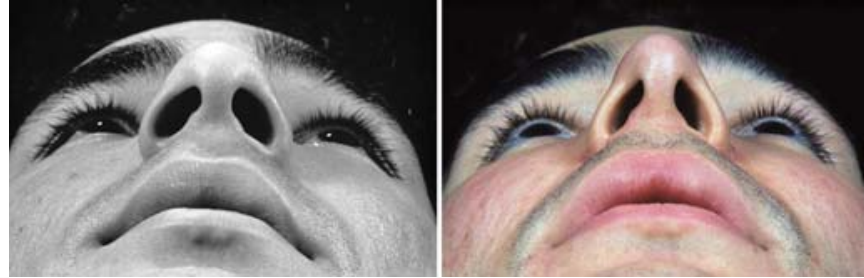

Fig. 9: Dorsal approach rhinoplasty, cosmetic. 21-year-old male, 9 months postoperative. Symmetrical narrowing of nose with thick skin and subcutaneous tissues

anesthetic. It included nasal dermabrasion, full exposure of nasal tip and dorsum via supratip 'eagle wing' incision, profile reduction of bony and cartilaginous dorsum (with periosteal preservation), osteotomies with in-fracturing of the bony nasal sidewalls, modified Goldman tip procedure (to gain tip projection), resection of thick SMAS and subcutaneous tissues, graduated supratip skin excision, and bilateral alar base wedge resection, $3 \mathrm{~mm}$ per side. Care was taken to not increase tip rotation or open the satisfactory nasolabial angle.

The supratip skin strip excised was $5 \mathrm{~mm}$ wide at its center, and incorporated the two largest intracutaneous sebaceous cysts. The skin exuded whitish 'milk' from densely-packed dilated sebaceous glands at the incision margins. The skin incision curved cephalically, away from the alar lobules at the incision tips, to lie in a natural depression of each lateral supratip sidewall and 'hide' slightly behind the superior aspect of each alar lobule flare.

One of the most striking features of this case was the extreme thickness of the subcutaneous tissues. A sheet of subcutaneous tissue was excised in the immediate subdermal plane using fine curved scissors. It measured $3.5 \mathrm{~cm}$ in width by $5 \mathrm{~cm}$ in length, and varied in thickness from $2.5 \mathrm{~mm}$ at the nasion to $5 \mathrm{~mm}$ in the region of the anterior septal angle.

Postoperative recovery was uneventful. Splint and sutures were removed on the sixth postoperative day. By the third postoperative week, he was very pleased with the appearance of his narrowed nose, despite the violaceous appearance of the dorsal supratip scar. In fact, he did not return for further follow-up until 9 months later, stating that he was so happy with the appearance of his 'new' nose he did not see any point in coming back sooner, until requested to do so for postoperative photography. The nose remained nicely narrowed and the dorsum was seen to be symmetrical and straight in both frontal and profile views, except for having developed a new acne cyst in the supratip region (Figs 6 to 9). He was referred for continuing dermatologic care. 


\section{Case 2}

A 66-year-old man complained of chronic left nasal obstruction and was concerned about the appearance of his nose. He had had two septal submucous resections, at ages 19 and 30 years, with a history of subsequent nasal reinjury. Rhinophyma surgery, consisting of surgical planing, had been carried out by a general plastic surgeon approximately 5 years prior to first consultation with the author. ${ }^{58}$ He had been advised nothing further could be done regarding the appearance of his nose. There was some recent history of recurrent anterior epistaxis.

He was noted to have a large, bulbous nasal tip with marked tip droop, columella retraction and consequent nostril 'hooding' (Fig. 10). Manual elevation of the nasal tip by upward traction on the dorsal nasal skin gave significant relief of partial right nasal breathing obstruction, previously unrecognized by the patient because of the severity of the obstruction on the left. Highly visible flat, shiny scars of each inferolateral nasal sidewall contrasted with large-pored, pebbled nasal skin. The entire nasal tip, particularly the medial crura, had a rather 'skeletonized' appearance. There was notching of the superolateral nostril margins. Intranasally, he was found to have severe deviation of the anterior septum to the left, and a $1 \mathrm{~cm}$ in diameter chronic septal perforation located at the junction of anterior and mid-septum. He was referred for a dermatologic assessment and diagnosed as having sebaceous hyperplasia of nasal and facial skin.

For all of the above reasons, dorsal approach rhinoseptoplasty was recommended. Aside from improving the appearance of the nose, it was felt that debulking of the

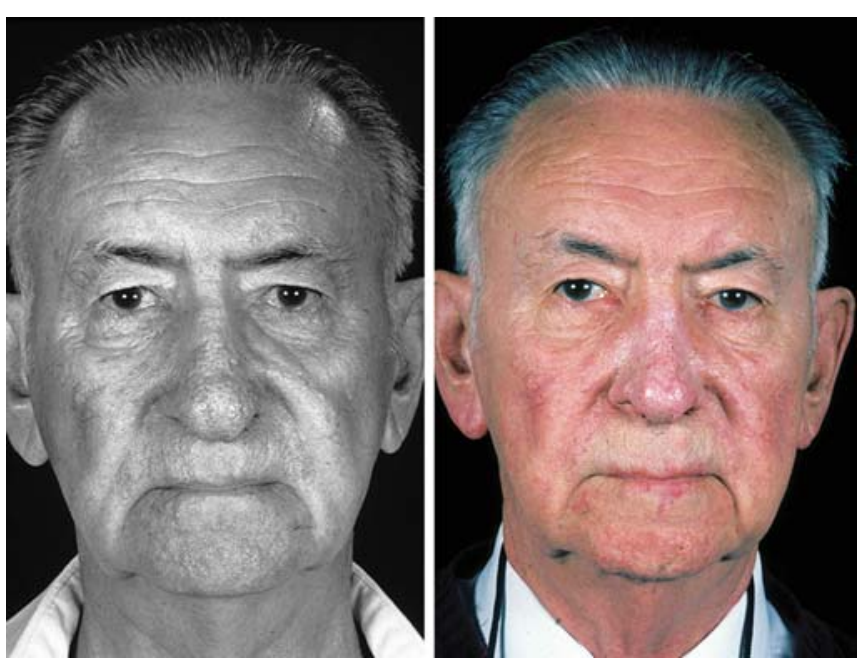

Fig. 10: Dorsal approach rhinoseptoplasty, cosmetic and functional. 66-year-old male, 9 months postoperative. Previous rhinophyma surgery, with scarring and rigid-skin nose. Very acceptable dorsal nasal 'Eagle-Wing' incision scar nasal tip cartilages could provide sufficient crural cartilage to reinforce the septal mucosal flaps during repair of the chronic perforation. Narrowing, debulking and elevating the nasal tip were considered possible only if direct excision of the scarred lateral supratip skin was carried out simultaneously along with correction of the skeletal infrastructure deformities.

Dorsal approach rhinoseptoplasty and chronic perforation repair were carried out simultaneously. Nasal dermabrasion was carried out to minimize the planned dorsal incision scar, 'eagle wing' incisions were made to excise skin of the supratip and lateral nasal sidewalls, allowing upward tip rotation, tip debulking and excision of the unsightly nasal sidewall scars. The initial incision was made down to the perichondrial level. The dorsal cutaneous hinge flap was thinned, excising a thick layer of sub-Q and SMAS $3 \mathrm{~mm}$ thick, $3.5 \mathrm{~cm}$ long and $3 \mathrm{~cm}$ wide. This was followed by excision of the subcutaneous tissues overlying the tip domes and lateral crura. Subcutaneous elevation via the dorsal approach was carried down well into the columella, at the caudal margins of the medial crura, to permit repositioning of the ptotic left tip cartilage medial crus. Despite the previous skin planing of the primary rhinophyma surgery, the skin itself was still noted to be very thick and packed with hypertropic sebaceous glands.

The caudal margin of the septal cartilage was exposed by dividing the intercrural ligaments and bivalving the membranous septum, revealing severe buckling to the left and weakness of the caudal and dorsal cartilage struts. Insufficient septal cartilage remained to permit both septal reconstruction and repair of the chronic septal perforation. This problem was overcome by resecting a $1.5 \mathrm{~mm}$ thick segment of dorsal nasal hump and grafting it to the right side of the weak caudal strut, trephining the bony portion to enable it to be sutured to the right side of the nasal spine. The cartilage portion was mattress sutured to the weak, bowed cartilage strut and anterior septal angle. A thin, strong strip of septal cartilage, salvaged from above the chronic perforation, was grafted between the transected margin of the right upper lateral cartilage and quadrangular cartilage, to repair the weak dorsal strut and correct medial depression of the right upper lateral nasal cartilage (right spacer graft). Resected cephalic segments of the lateral crura were used to replace absent septal cartilage at the site of chronic perforation repair, carried out using 'flip-flop' flaps of septal mucoperichondrium.

Tip reduction was carried out using a modified Goldman tip technique, with vertical dome division and trimming of the medial ends of the lateral crura, as the dome angles were noted to be very wide and obtuse. All tip work was done without intranasal incisions. 
Using the technique of overlapping the caudal eagle wing incision with the dorsal hinge flap (with the reconstructed tip rotated to the desired position), graduated skin strip incision was carried out, starting with a vertical dart at the center ' $V$ ' of the dorsal flap. The resected skin strip was $8 \mathrm{~mm}$ wide at its center and incorporated all of the lateral rhinophyma planing scar at the left side of the nose, and $3 / 4$ of that on the right. The excision apices ended at the upper lateral nasal sidewalls, at each junction of upper lateral cartilage with nasal bone. The cutaneous excision defect was closed with interrupted 6-0 nylon sutures. Via a small columella base incision, some of the resected sub-Q/ SMAS tissue was repositioned between the feet of the medial crura to act as a 'plumping' graft. At the conclusion of the case, profile and symmetry of the nose were judged to be satisfactory, though upward tip rotation had revealed the full extent of notching of the nostril margins from scarring and contracture of the planed, rigid rhinophymatous skin.

Postoperative recovery was unremarkable, and the plaster splint and anterior nasal packing were removed on the second postoperative day while the dorsal nasal sutures were removed on the sixth postoperative day along with the remaining eschar from nasal dermabrasion.

The bilateral nostril notching was corrected at a second surgery 3 months later, at which time small composite grafts of the anterior limb of each crus helicis were grafted into intravestibular incisions made cephalic to each nostril rim. Residual columellar overhang was corrected by resection of $1.5 \mathrm{~mm}$ strips of skin and cartilage at the caudal margins of the medial crura. Minor revision of a slightly broadened and depressed scar at the ' $\mathrm{V}$ ' apex of the previous eagle wing resection was also carried out along with thinning of the right side of the septum at the vestibular 'valve' region. A further 3 months later, he reported normal breathing through both nostrils and was very pleased with the external appearance of his nose. The chronic perforation was completely healed. Postoperative photographs obtained 9 months following the dorsal approach rhinoplasty and 6 months after correction of residual nostril deformities, show very satisfactory correction of the external deformities, minimally-visible dorsal supratip scar, and excellent correction of the lateral nasal scarring caused by the original rhinophyma surgery (Figs 10 to 13).

\section{DISCUSSION}

While this paper focuses on a rhinoplasty technique I have named the 'dorsal approach rhinoplasty', it should be appreciated that I use conventional or closed methods, making endonasal incisions only, in the large majority of
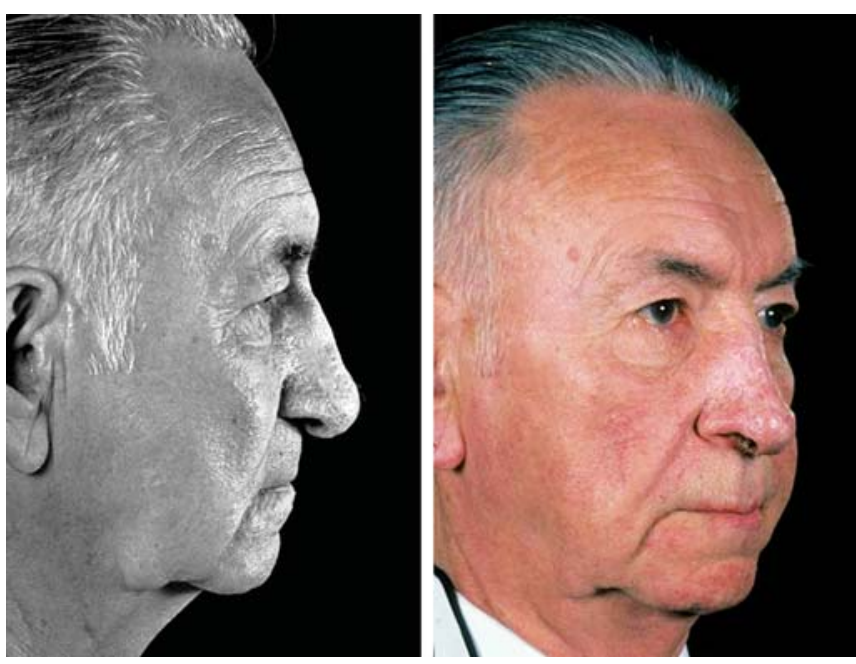

Fig. 11: Dorsal approach rhinoseptoplasty, cosmetic and functional. 66 -year-old male, 9 months postoperative. Correction of tip ptosis and reduction of scarring from previous rhinophyma surgery in rigidskin nose
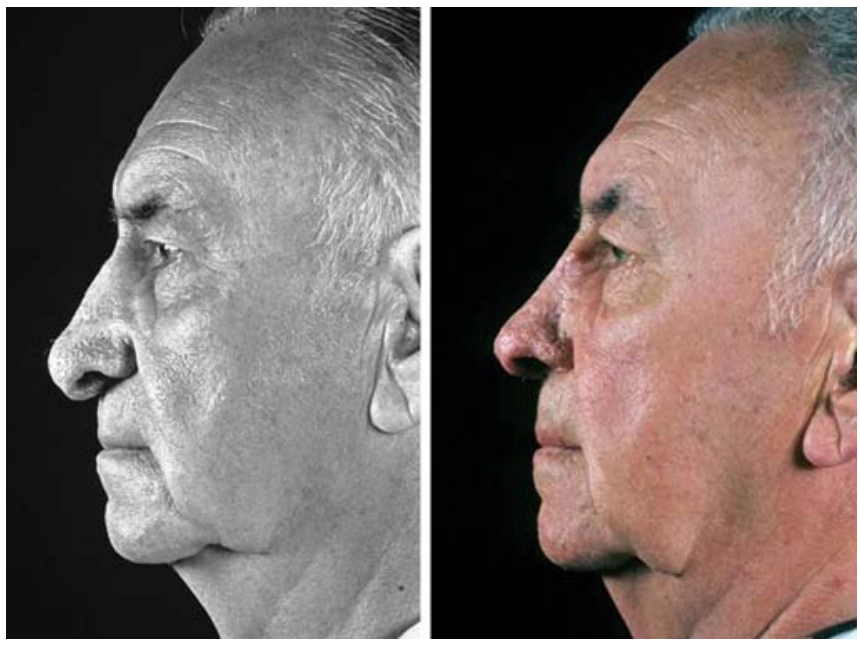

Fig. 12: Dorsal approach rhinoseptoplasty, cosmetic and functional. 66-year-old male, 9 months postoperative. Improved nasal profile, correction of tip ptosis and reduction of scarring from previous rhinophyma surgery in rigid-skin nose
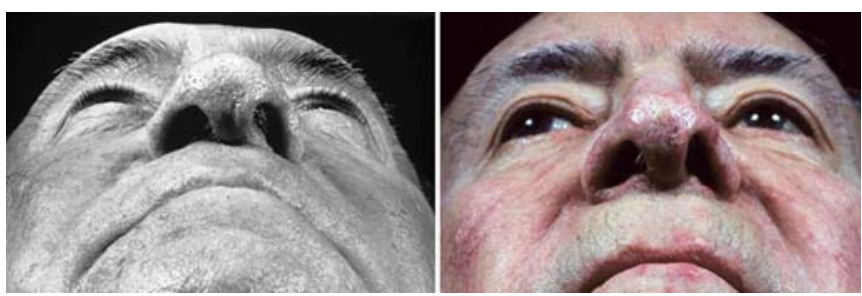

Fig. 13: Dorsal approach rhinoseptoplasty, cosmetic and functional. 66-year-old male, 9 months postoperative. Debulking of scarred, ptotic nasal tip and dorsum (with correction of left obstructive septal deviation and chronic septal perforation) in rigid-skin nose from previous rhinophyma surgery

both cosmetic (Figs 14A to F) and corrective (Figs 15 and 16) noses. The creation of additional scars should be avoided whenever possible, whether intranasal or external. However, I readily resort to the external or open rhinoplasty (Figs 17 and 18) whenever the benefits of this approach outweigh 

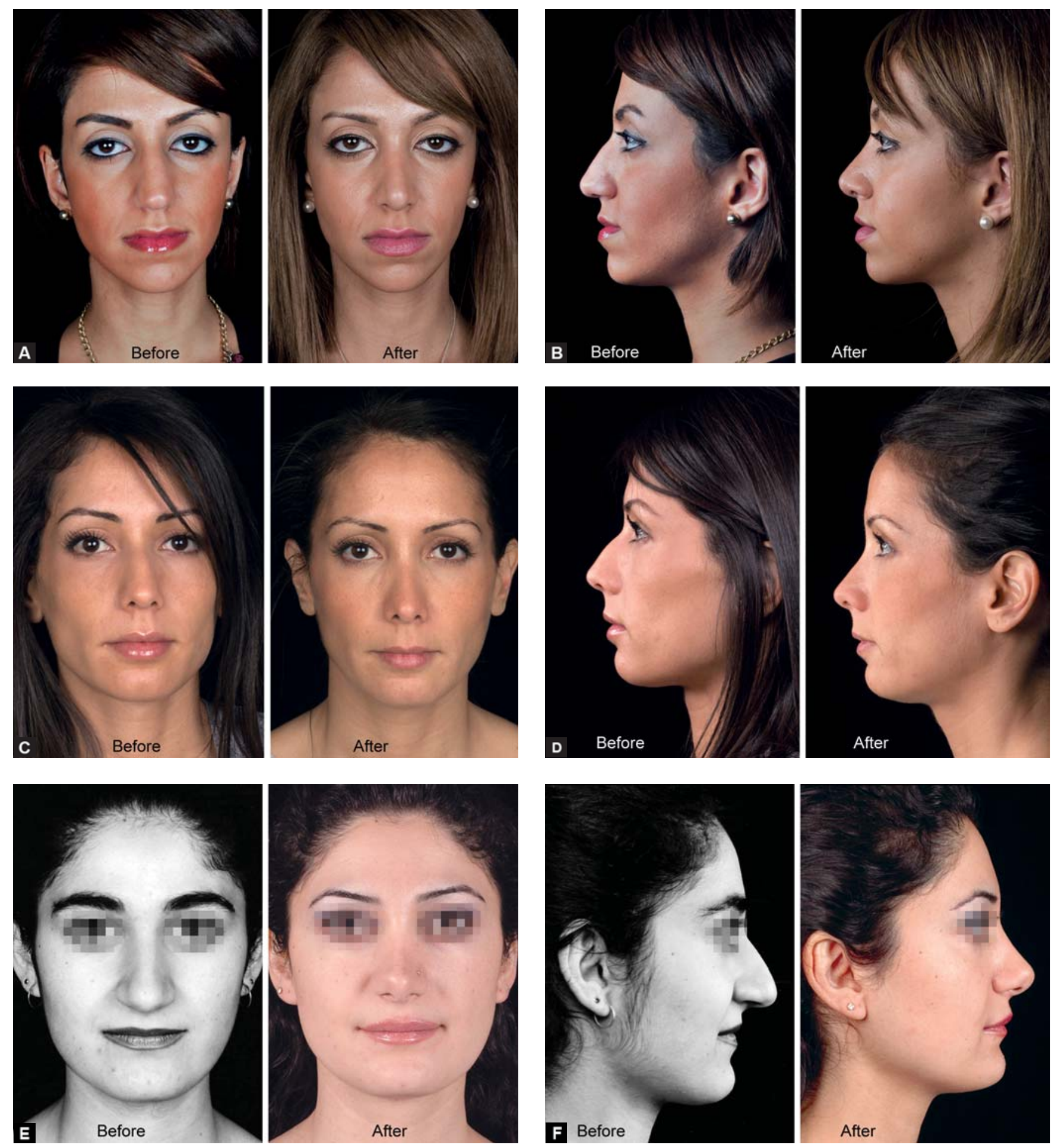

Figs 14A to F: Conventional closed technique cosmetic rhinoplasty -1 year pre- and postoperative views

the presence of what should be a barely-visible transcolumellar scar (Figs 19 and 20A to C). Since carrying out my first external approach rhinoplasty in 1974, this technique has comprised 10 to $15 \%$ of my rhinoplasty cases. Of these, less than $10 \%$ have been purely cosmetic. For the rest, the external approach has provided solutions to many challenging nasal deformities (Figs 21 to 24). Superior results have been achieved in many of these cases, likely because of the precision with which repairs of the nasal skeleton can be carried out under full exposure and direct visualization (Figs 25A to $\mathrm{C}$ and 26 A to C).

As in the conventional rhinoplasty, however, good results with the external approach are dependent upon having relatively normal skin. Bulky skin defeats cartilage and bone work. The transcolumellar external approach cannot handle the additional problems presented by thick, 

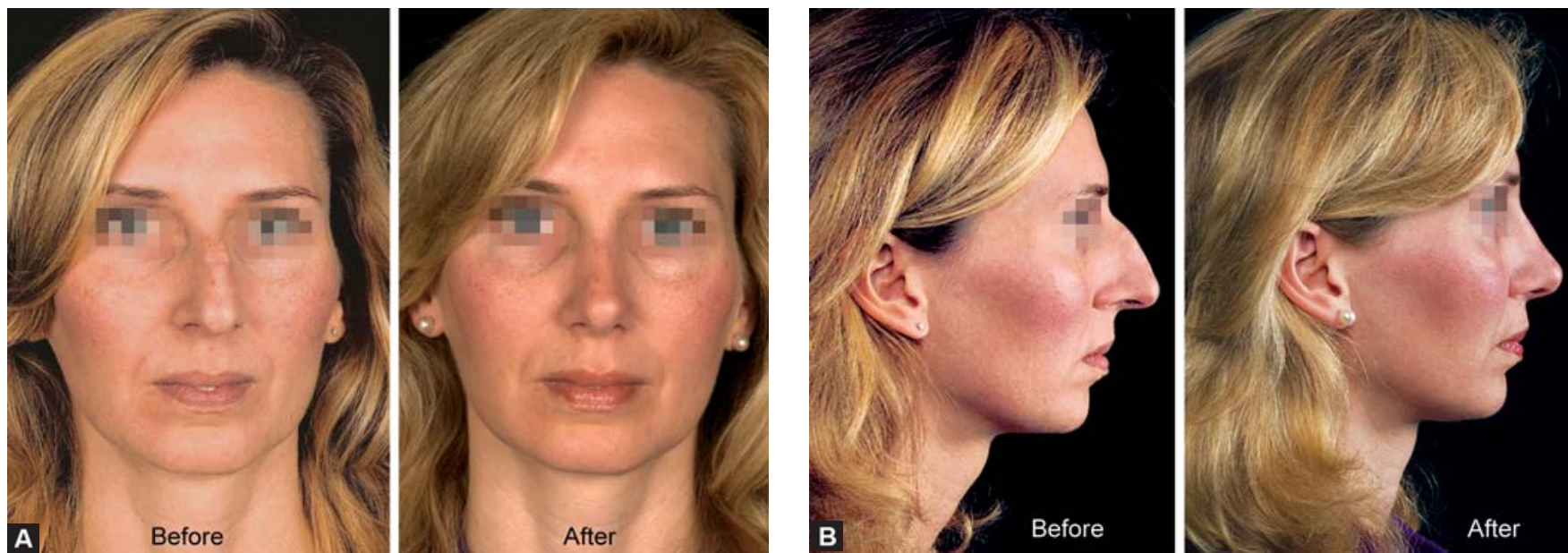

Figs 15A and B: Conventional closed technique cosmetic and corrective rhinoplasty-1 year pre- and postoperative views
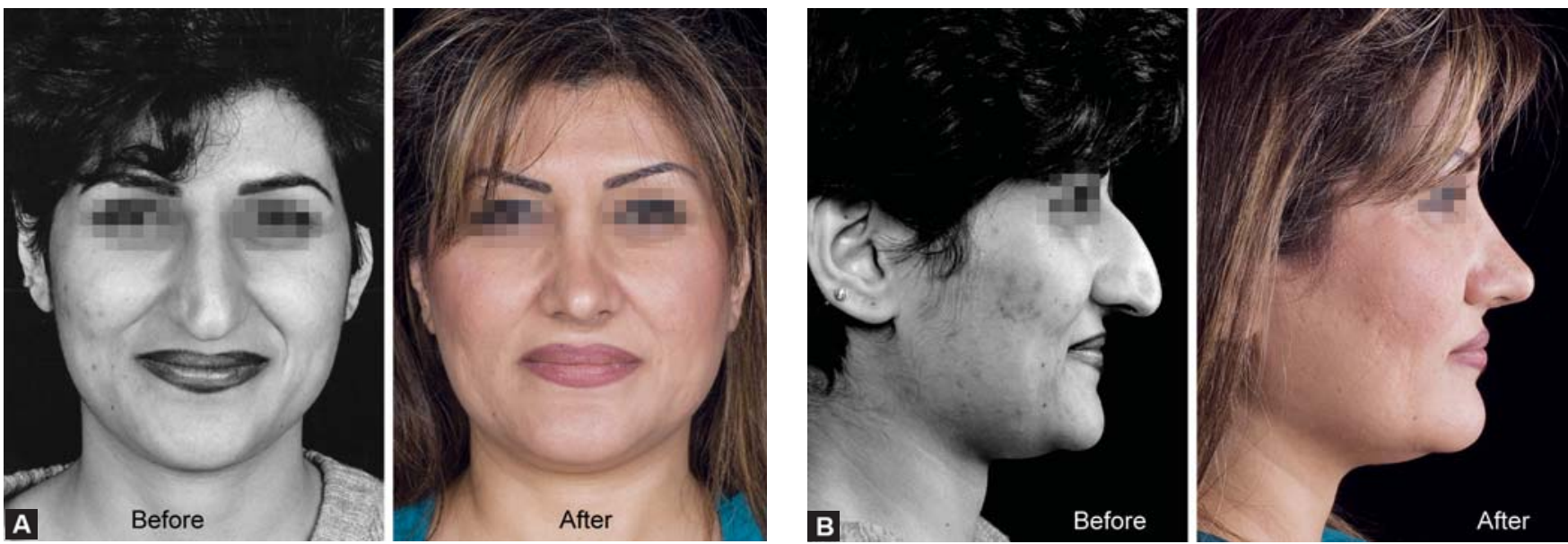

Figs 16A and B: Conventional closed technique cosmetic and corrective rhinoseptoplasty-1 year pre- and postoperative views
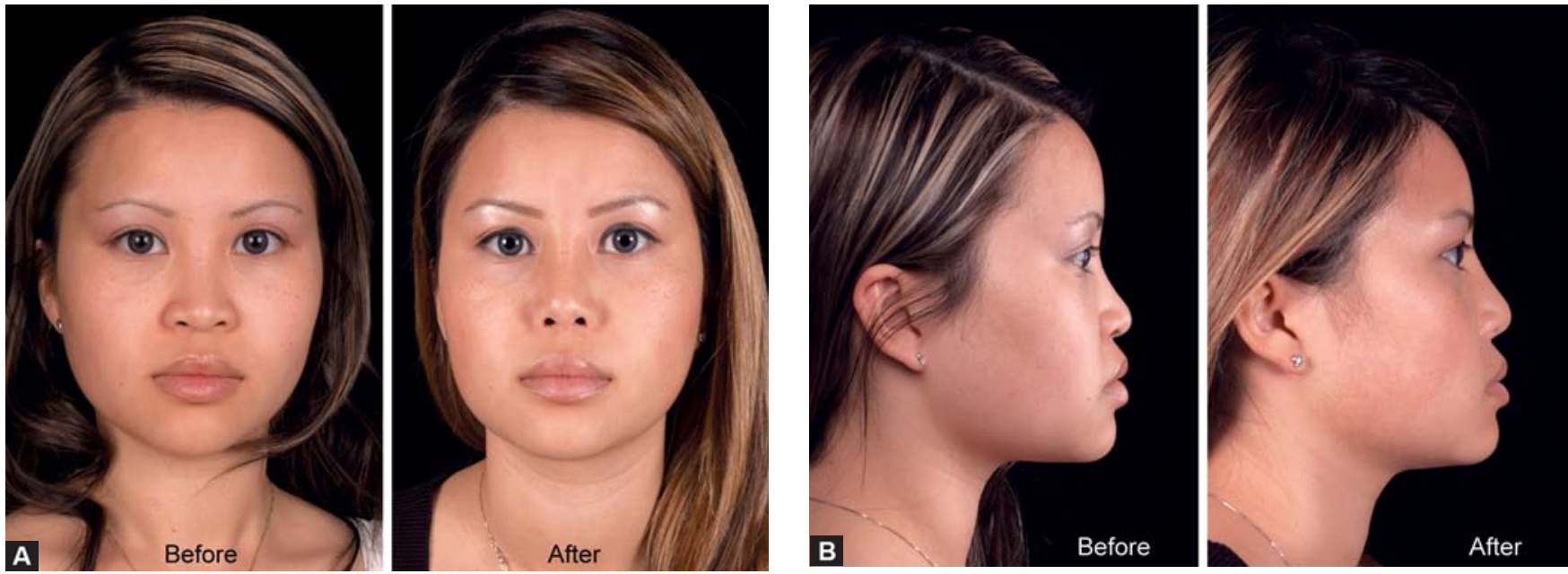

Figs 17A and B: External approach cosmetic rhinoplasty-1 year postoperative. Enhancing height of nasal bridge with nasal implant plus tip narrowing

rigid or scarred skin of the nasal tip and dorsum. It is to this end, achieving satisfactory esthetic results in the rigid skin nose, that I have designed and adopted the eagle wing incision.
Other direct dorsal incisions have, of course, been utilized in the past to approach the nasal dorsum when solving certain difficult nasal problems (see Table 3 and Figs 27 and 28). The skilled rhinoplastic surgeon would do 

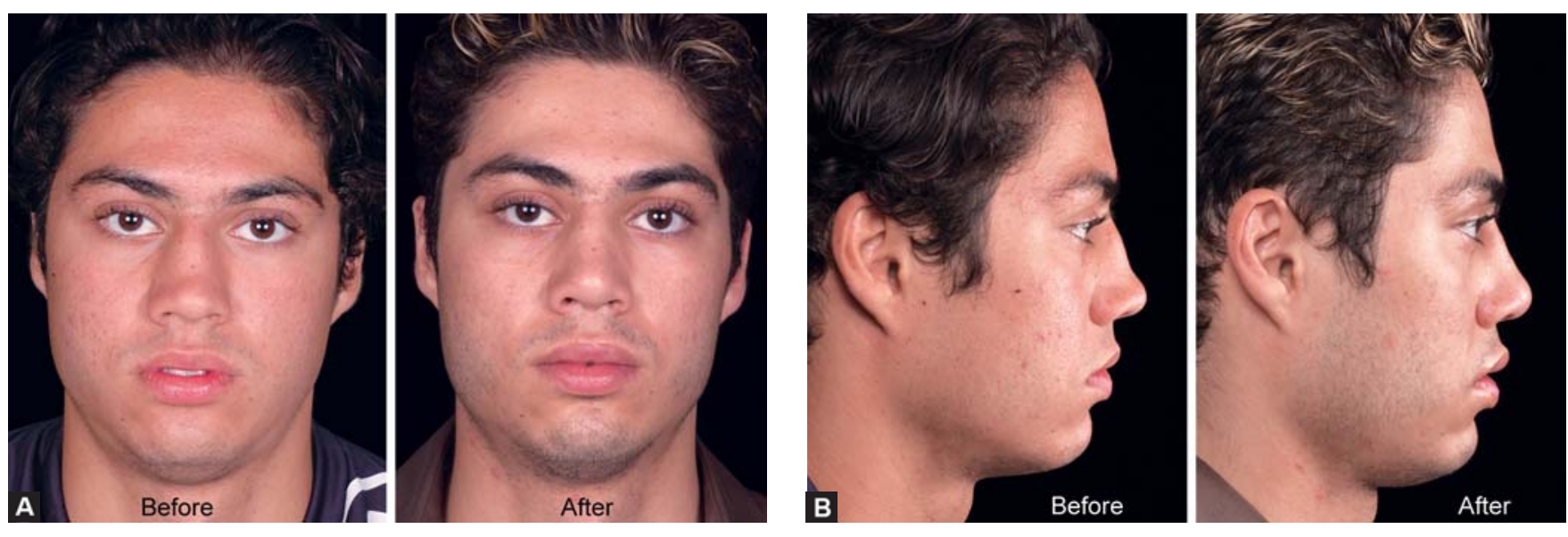

Figs 18A and B: External approach rhinoplasty repair of saddle nose deformity -1 year postoperative views
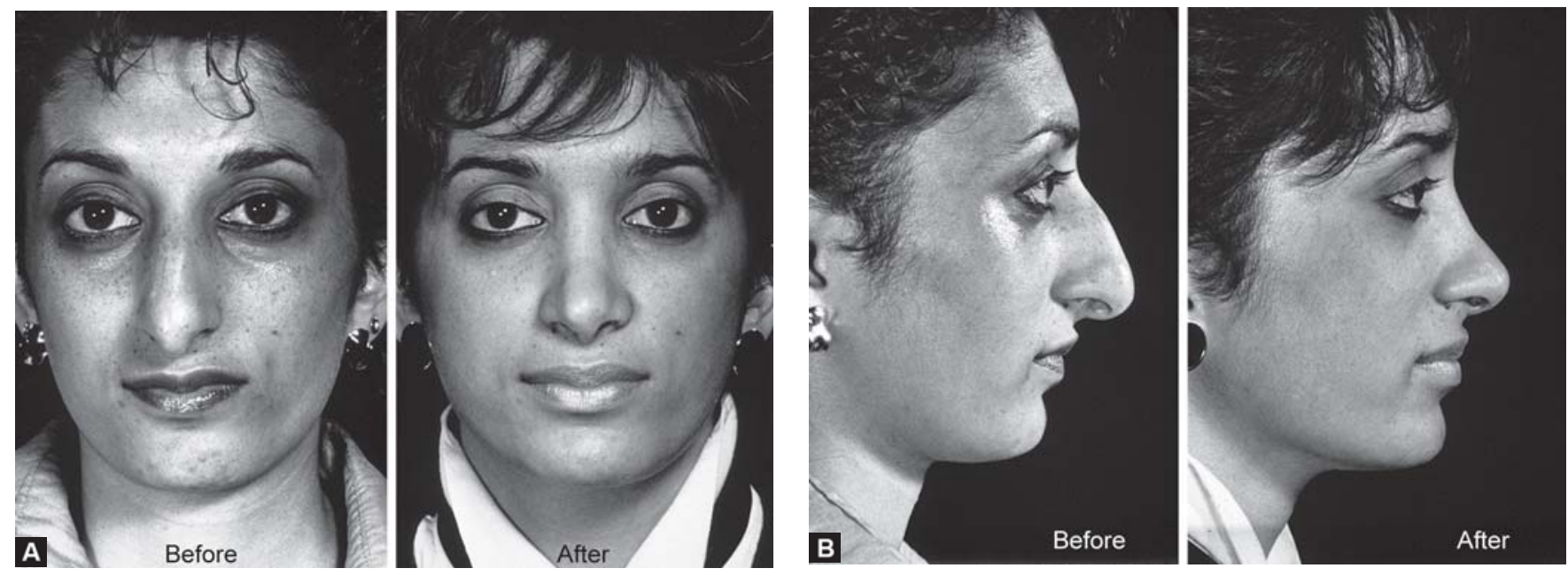

Figs 19A and B: External approach cosmetic rhinoplasty -18 months pre- and postoperative views
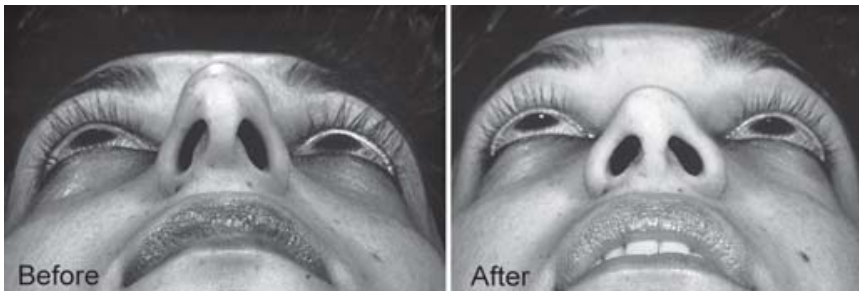

Fig. 19C: External approach cosmetic rhinoplasty-18 months pre- and postoperative views showing barely visible transcolumellar incision scar

well to become familiar with all of these external excision possibilities. Figures 29 to 31 show where I would use the transverse subnasion incision and the gull wing incision. With each of these incisions, intraoperative dermabrasion is useful in minimizing the resultant external cutaneous scar (Figs 31 to 33).

With regard to the new 'eagle wing' incision described, several points have to be emphasized. As opposed to what is commonly known as the 'gull wing' or 'seagull wing' incision, the tips of which turn downward (see Fig. 31), the
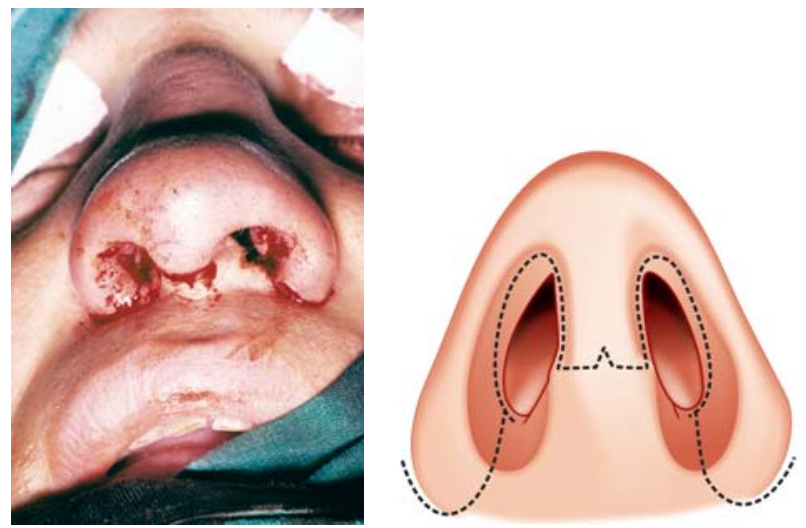

Fig. 20A: External approach rhinoplasty: Classic transcolumellar and bilateral alar base (Weir) incisions

eagle wing incision curves dorsocephalically away from the alar groove (Fig. 34). This avoids a rotund, demarcated lobule, isolated from the rest of the nasal sidewall by scar. Forces of contraction pulling superiorly blend and smoothen the scar instead of deepening the groove or dip between alar lobule and the rest of the nose. 


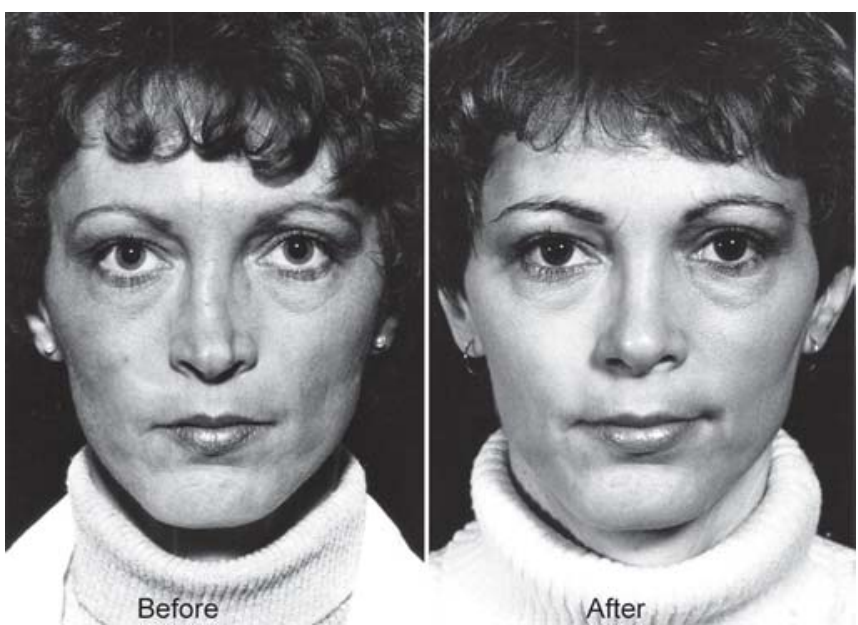

Fig. 20B: External approach rhinoplasty repair of severe previous nasal surgery deformities with rib and composite ear grafts to nasal dorsum and tip
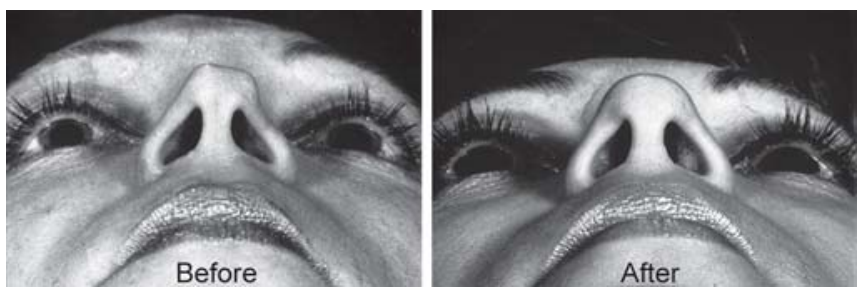

Fig. 20C: External approach rhinoplasty repair of severe previous nasal surgery deformities-18 months postoperative views with rib and composite ear grafts to nose. Note: Barely visible transcolumellar incision scar
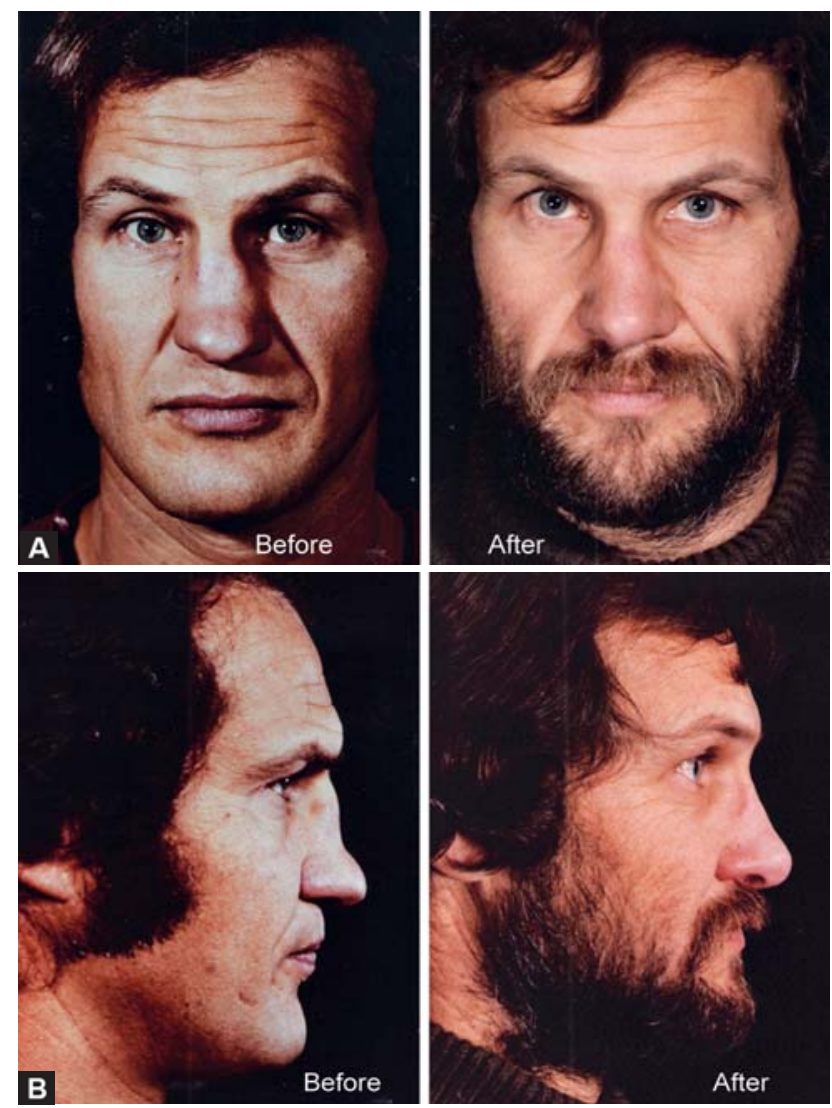

Figs 21A and B: External approach rhinoplasty repair of saddle nose deformity -6 years postoperative views. Note: No autografts or allografts were employed in carrying out this procedure
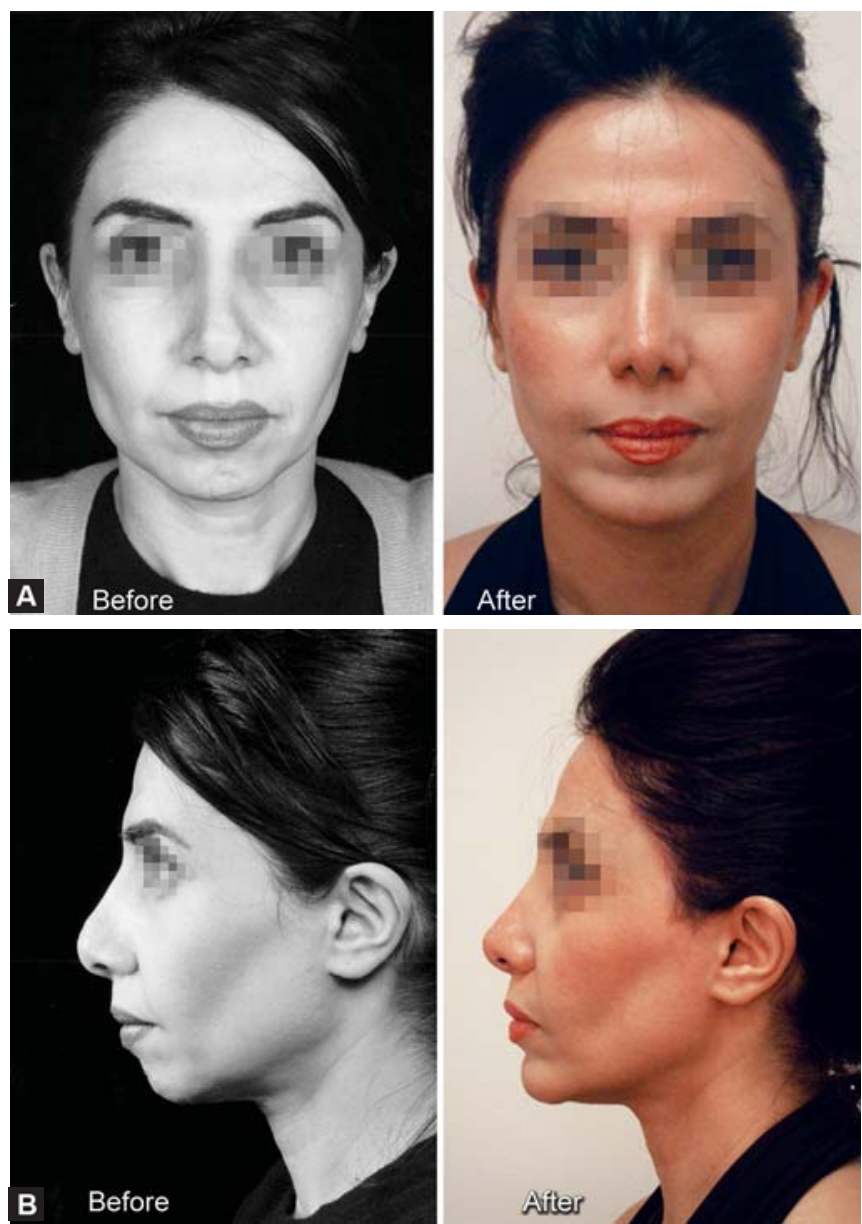

Figs 22A and B: External approach revision cosmetic rhinoplasty plus chin implant-18 months pre- and postoperative views

The eagle wing incision, with upward tilt of the 'wing tips', provides increased dorsal nasal exposure up to the nasion and glabella (Table 3). Even with long 'wings', good length-to-width ratio of the resultant dorsal hinge flap can still be maintained. In the bulky nose, thick skin, thick subcutaneous tissues and thick SMAS all have to be assessed and resected according to need. Vascular supply and drainage of the cephalic hinge and caudal tip flaps should be well maintained, provided a thin subdermal layer is left attached to the dermis when SMAS and subcutaneous layers are resected.

Graduated excision, determined by overlapping the caudal tip flap with the cephalic hinge flap, is the preferred method for resecting the redundant supratip skin. This avoids potential errors in tip positioning which might result from overzealous excision of dorsal skin at the commencement of the procedure. Despite the shorter length of the upper excision margin compared to the lower margin, the eagle wing shape of the resection defect permits coaptation adjustments along the full length of the curved margins thus avoiding dog ear or similar skin closure deformities. 

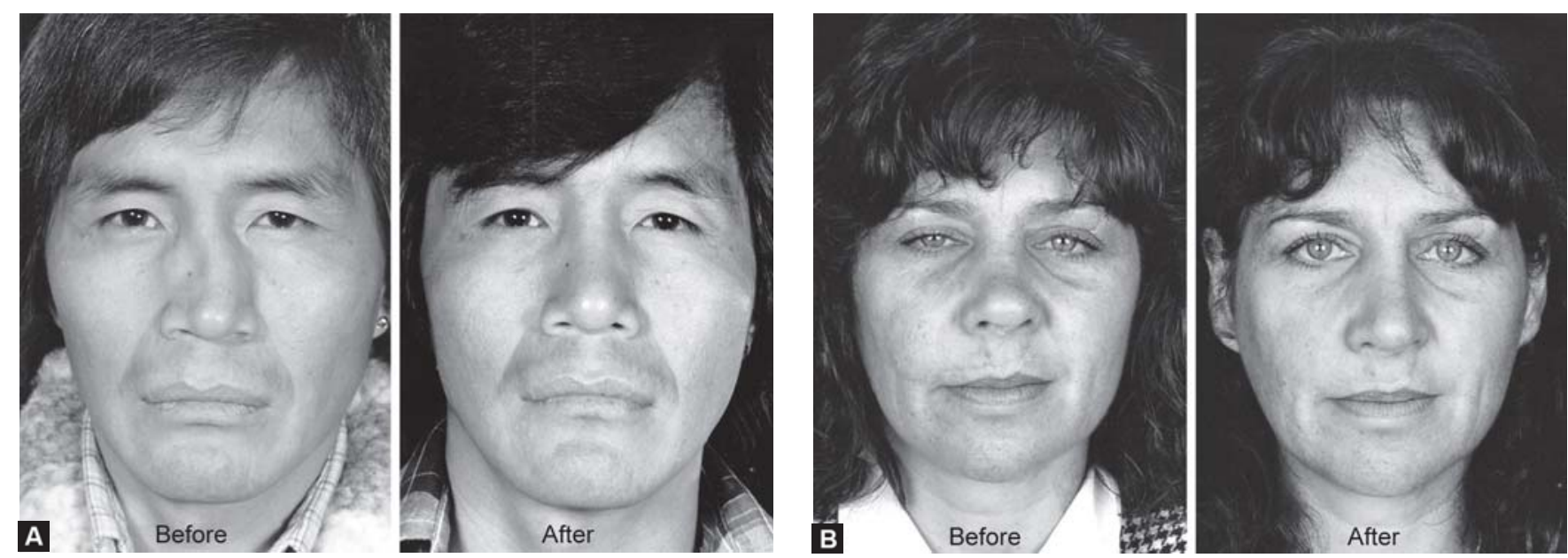

Figs 23A and B: External approach rhinoseptoplasty repair of severe nasal injury deformities-18 months pre- and postoperative views
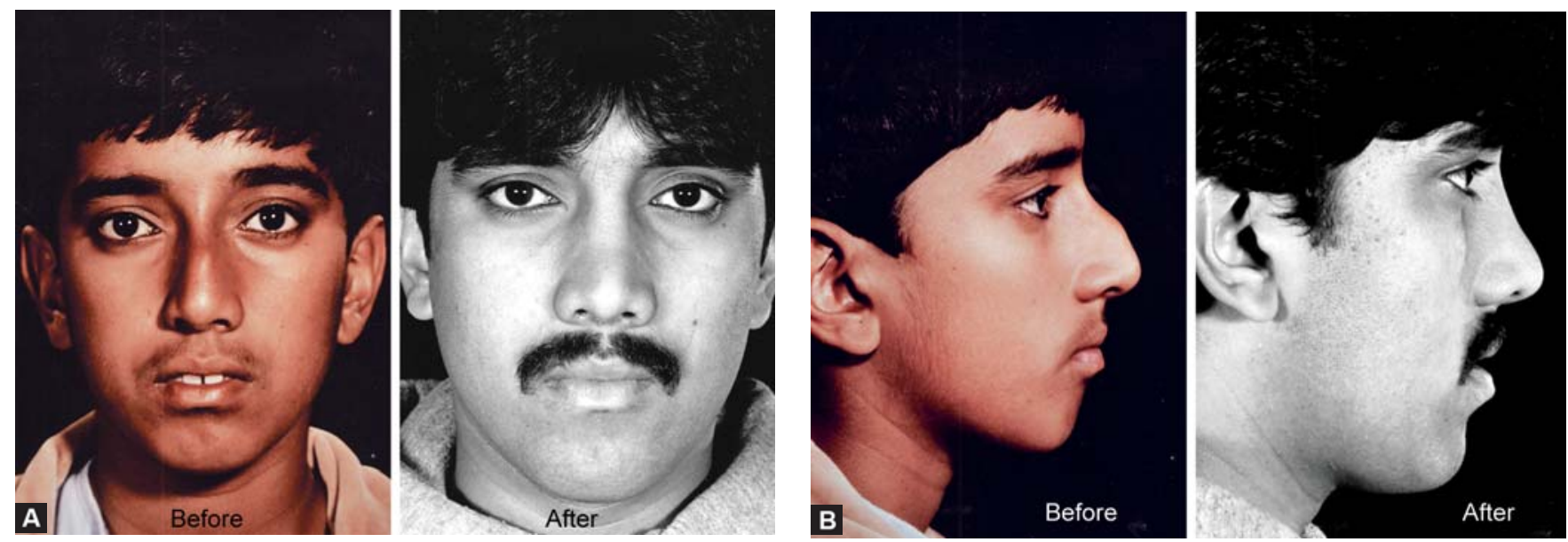

Figs 24A and B: External approach rhinoseptoplasty: 7 years later
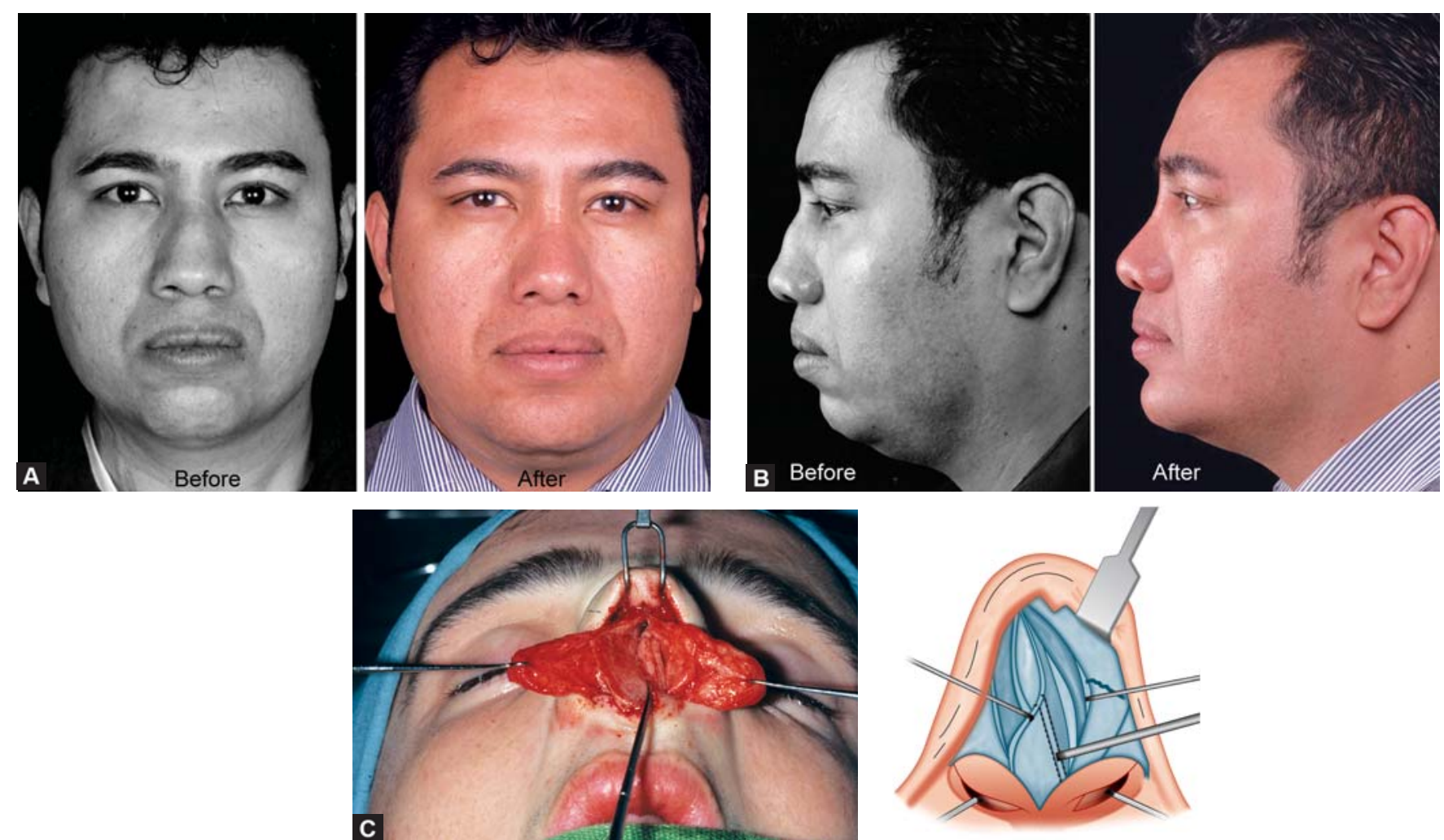

Figs 25A to C: External approach rhinoplasty repair of saddle nose deformity plus chin implant—One year pre- and postoperative views 


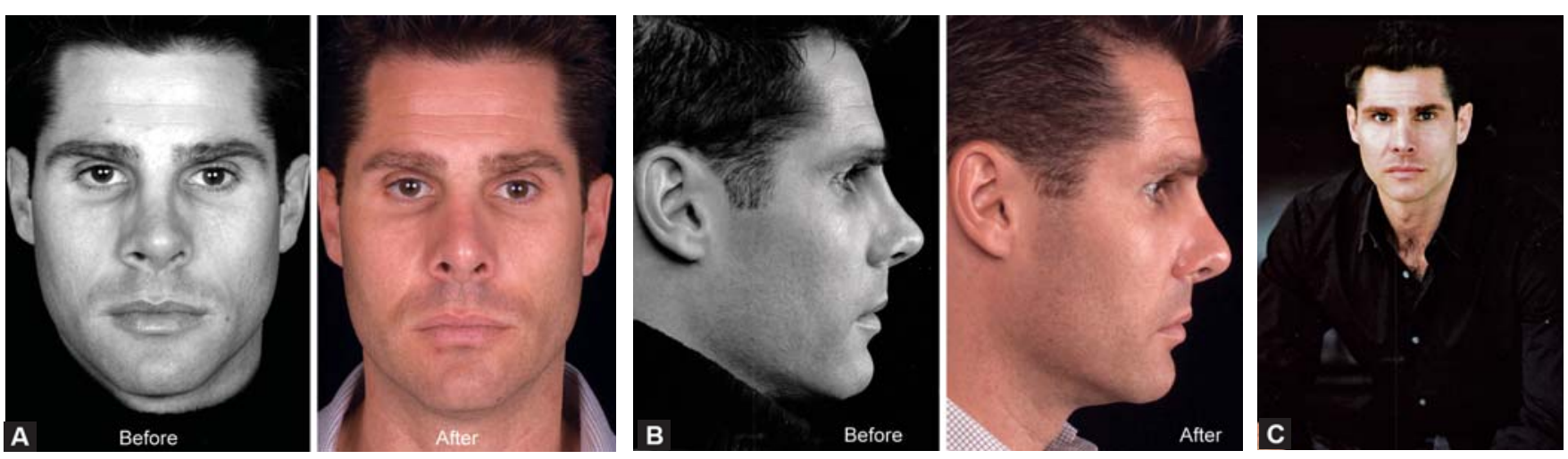

Figs 26A to C: External approach rhinoplasty repair of nasal deformities from two previous nasal surgeries-2-year pre- and postoperative views
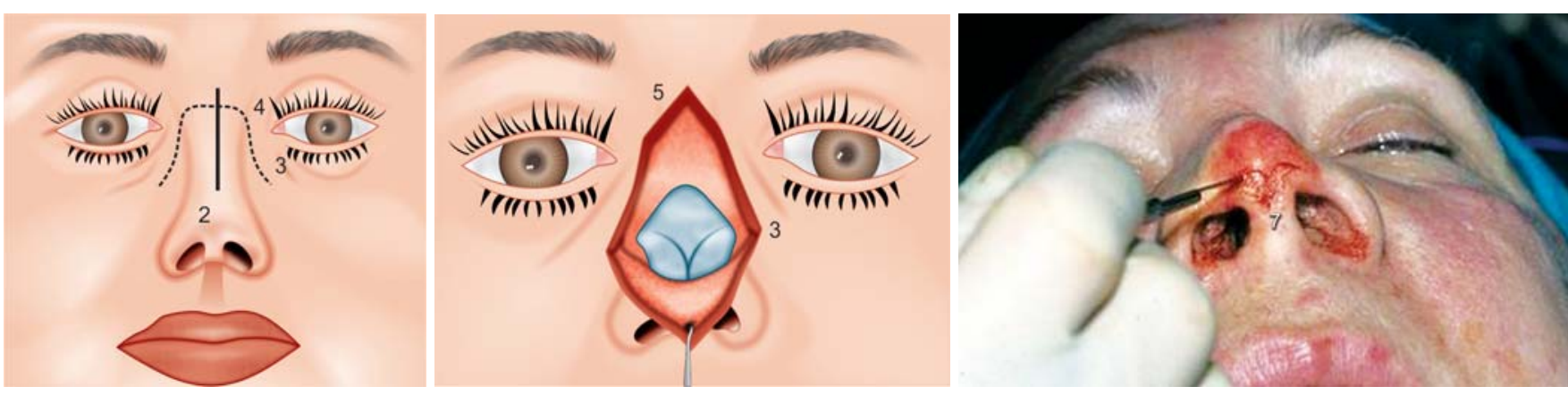

Fig. 27: Midline, lateral, transverse and inverted-V incisions (after Converse). ${ }^{6}$ The photo shows 'gull wing' tip incision to reduce height of infratip lobule (Dubeta KR)

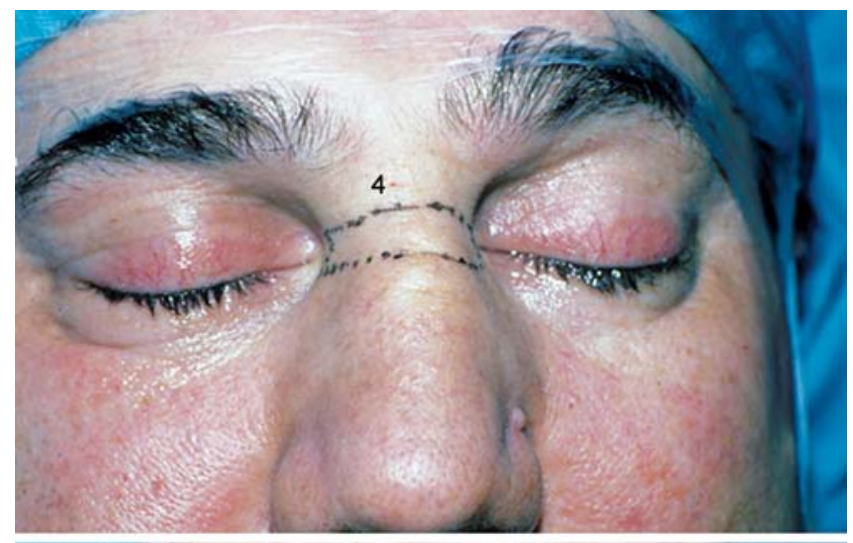

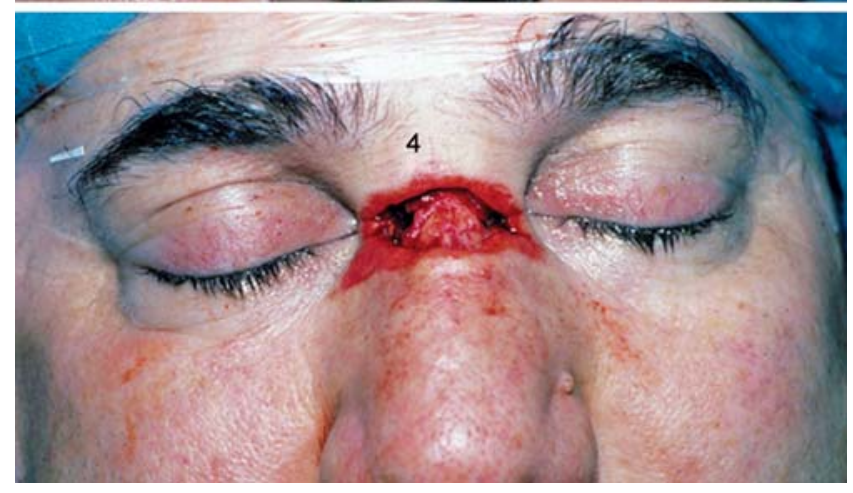

Fig. 28: The images show W-plastied subnasion/SMAS full thickness skin excision (Dubeta KR)
Table 3: Dubeta classification of dorsal nasal incisions (Dubeta KR, 1991)
1. Through scars
2. Midline
3. Lateral, along frontal processes of maxillae
4. Transverse (subnasion)
5. Inverted $\mathrm{V}$ into glabella
6. Combinations of above
7. Gull-wing incision
8. Eagle-wing incision 

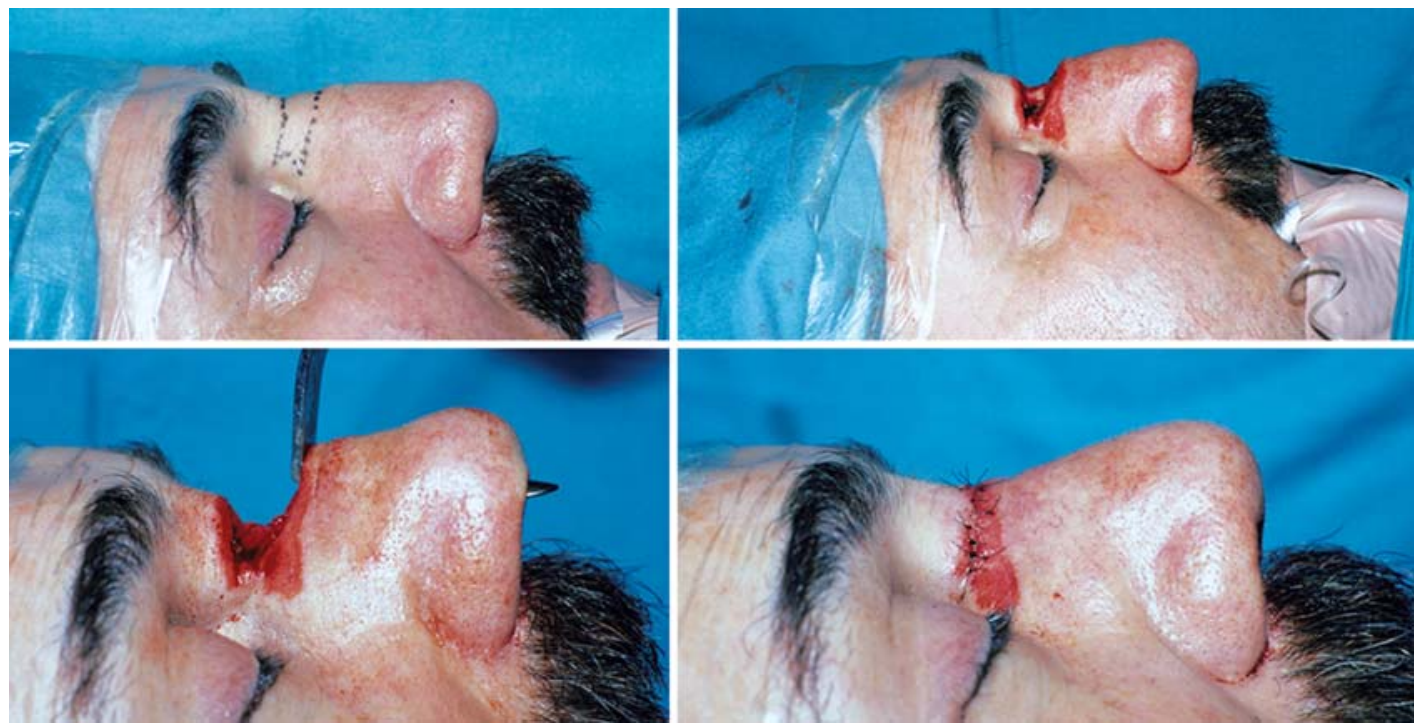

Fig. 29: Rigid-skin nose with nasal obstruction due to tip ptosis. Photos show $10 \mathrm{~mm}$ W-plastied subnasion/SMAS skin excision to allow upward mobilization of entire soft tissue envelope of nose
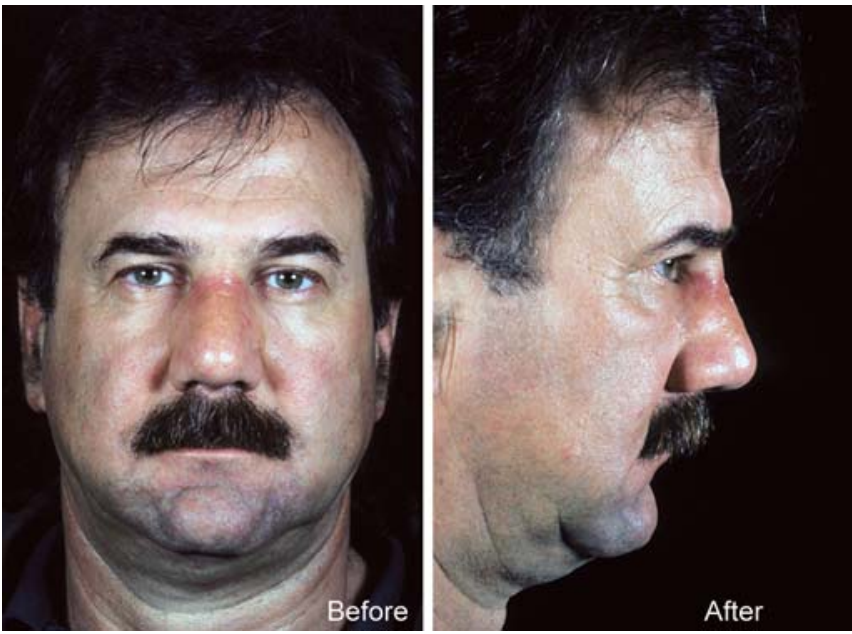

Fig. 30: Minimizing dorsal incision scars with dermabrasion: Dorsal subnasion approach rhinoplasty for extremely thick skin noseone week postoperative views

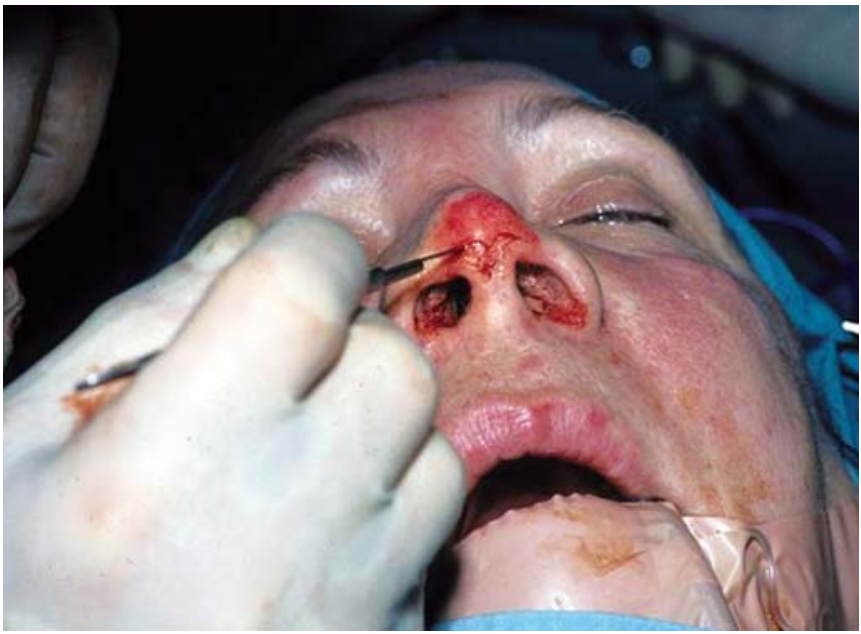

Fig. 31: Thick, rigid skin and excessive height of tip and infratip lobule, reduced with 'gull-wing' incision. Note: Caudally down-turned curvature of tips of incision 'wings'

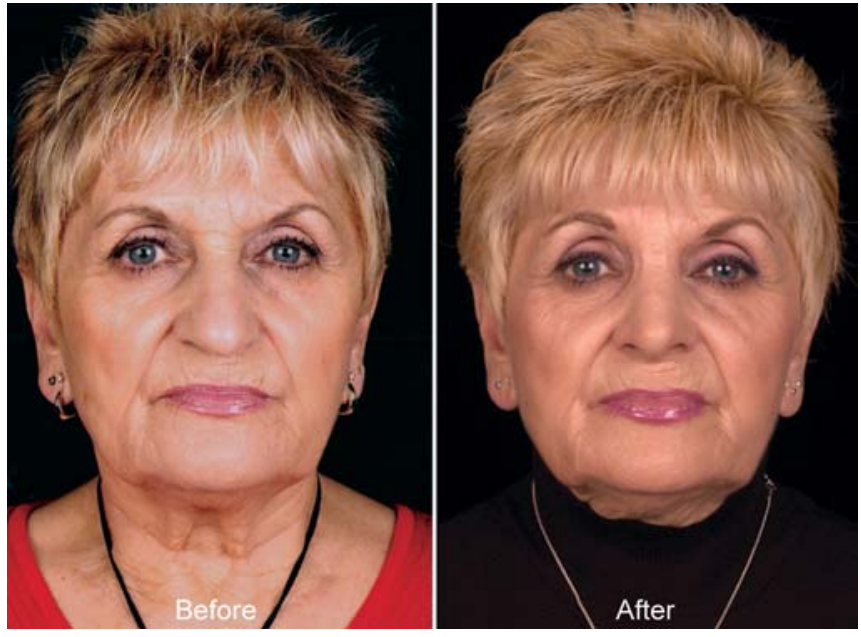

Fig. 32: Minimizing dorsal incision scar with dermabrasion: Dorsa approach cosmetic and corrective rhinoplasty with W-plastied excision of full thickness $10 \mathrm{~mm}$ nasion skin/SMAS strip-One year pre- and postoperative views
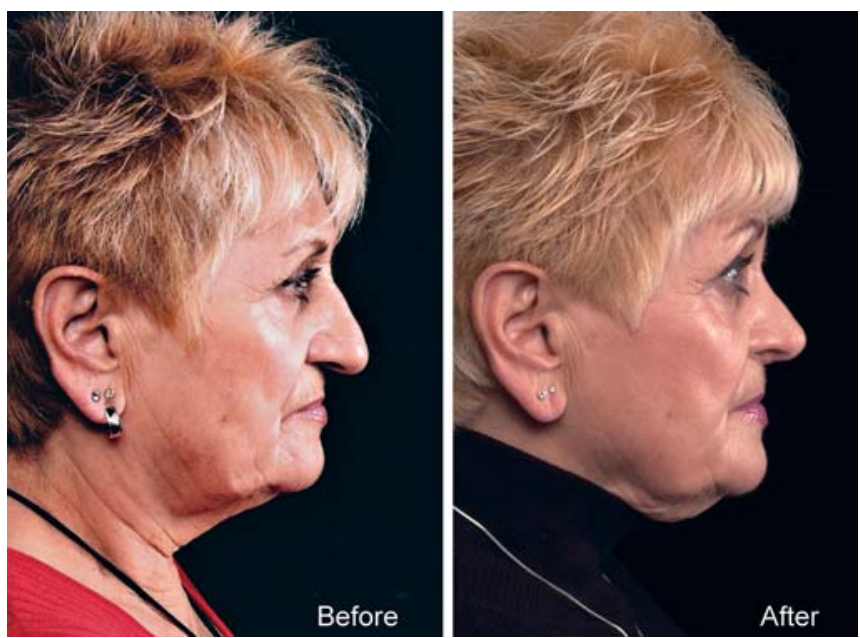

Fig. 33: Correction of aging nose skin laxity and structural changes causing nasal obstruction. Full thickness excision of dermabraded Wplastied $10 \mathrm{~mm}$ skin/SMAS strip-One year pre- and postoperative views 


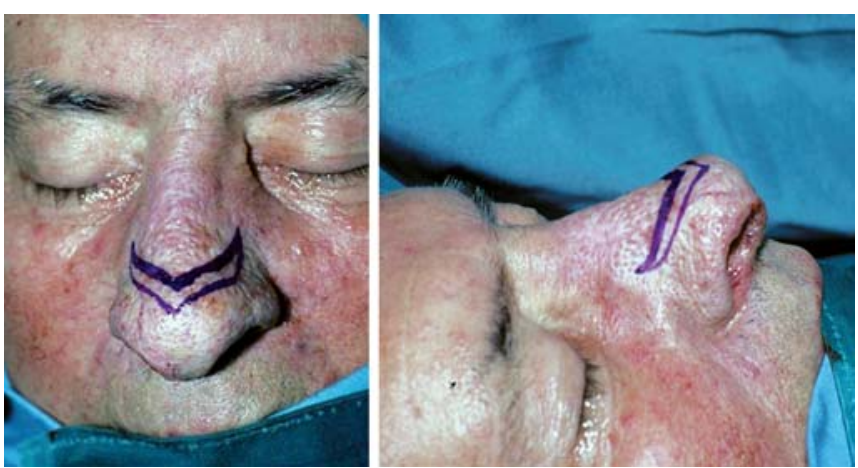

Fig. 34: 'Eagle Wing' incision detail: Note: Dorsocephalic curvature of tips of 'eagle wings', curving up and away from alar lobules (as opposed to downward curvature of gull-wing incision)

\section{CONCLUSION}

The dorsal approach rhinoplasty and eagle wing incisions are designed to resolve the problems of the rigid skin nose. Once again, the importance of patient selection, preoperative counseling and close postoperative follow-up cannot be emphasized enough. Patients with normal nasal skin will likely receive greater benefit from an alternative approach to the nasal dorsum, avoiding the possibility of a highlyconspicuous scar from unfavorable outcome. If proper psychological and selection criteria are met, however, the results of this approach can be most gratifying and will likely succeed, where conventional closed or open methods are doomed to fail.

The first part of this paper was entitled 'Dorsal Approach Rhinoplasty—Part 1: Historical Milestones in Rhinoplasty', and this historical view reminds us of the lesson: 'History repeats itself'. Built on a foundation of reconstructive rhinoplasty, modern cosmetic and corrective rhinoplasty have seen the parallel development of both open and closed techniques as 'new' methods are constantly introduced and reintroduced again. It is from the perspective of constant evolution in the art of rhinoplasty surgery that the author presents the dorsal approach rhinoplasty, as a hopefully valuable addition to the surgical armamentarium of the modern rhinoplastic surgeon.

\section{BIBLIOGRAPHICAL NOTE}

Plastic surgery of the nose has been contributed to by many surgeons, and all deserve corresponding credit. This monograph is intended to be a personal record of procedures I have found useful, rather than an encyclopedic compilation. There are long lists of references available in regular reference volumes and in many other published works. I endeavored to compile a list that would contain what articles present-day surgeons wished listed, but did not find complete interest or response.
In lieu of a complete comparative discussion of all the various recommended procedures, I wish to express our appreciation of, and dependency on, many procedures carried out by others, as have been made known to me by publication, personal communication and observation.

\section{REFERENCES}

1. Dingman R, Natvig P. Surgery of facial fractures, Philadelphia, WB Saunders Co., Chapter 2, The Men of the Elder Days 1964;88:11-42.

2. Fomon S. The Surgery of Injury and Plastic Repair. Baltimore: Williams and Wilkins Co. Chap XI, 'The Nose' 1939;18: 742-54.

3. Conway H, Stark R. Plastic surgery at the New York Hospital one hundred years ago (Chap V). New York, Paul B Hoeber 1953; pp 55-69.

4. Bishagratva, Kunja Lal. Susruta Samhita. Calcutta, JN Bose 1907. In: Seltzer AP. Plastic Surgery of the Nose (Chap 1). Philadelphia: JB Lippincott 1949;1-6.

5. Brown JB, McDowell F. Plastic Surgery of the Nose (Chap 1). St Louis: CV Mosby Co. 1951:pp 17-26.

6. Converse JM (Ed). Reconstructive Plastic Surgery (Chap 29) (2nd ed). Philadelphia: WB Saunders Co 1977;2:1209-12.

7. Rogers BC. Carl Ferdinand von Graefe (1787-1840). Plast and Reconstr Surg 1970;46(6):554-63.

8. Converse JM. New forehead flap for nasal reconstruction. Proc R Soc Med 1942;35:811.

9. Washio H. Retroauricular-temporal flap. Plast Reconstr Surg 1969;43:162-66.

10. Dieffenbach JF. Die nasenbehandlung. In: Operative Chirurgie, Leipzig FA Brockhaus 1845.

11. Fomon S. Cosmetic surgery, principles and practice (Chap 7). Philadelphia: JB Lippincott Co. 1960;258-59.

12. Roe JD. The deformity termed 'pug-nose' and its correction by a simple operation. Med Rec 1887;31:621.

13. Joseph J. Beitraege zur Rhinoplastik. Berl Klin Wahnschr 1907;46:470.

14. Joseph J. Nasenplastik und sonstige Gesichtplastik nebst Mammaplastik, Leipzig 1931 Curt Kabitzsch, First edition 1928.

15. Joseph J. Operative reduction of the size of a nose (rhinomiosis). Berlin Klinische Wochen schrift 1898;40:882. In: Aufricht (Ed). Plast Reconstr Surg 1970;46:178-83.

16. Aufricht G. 'Combined nasal plastic and chin plastic: correction of microgenia by osteocartilaginous transplant from large hump nose. Am J Surg 1934;25:292.

17. Safian J. Corrective Rhinoplastic Surgery. New York: Paul B Hoeber 1935.

18. von Mangoldt F. Reconstruction of saddle nose by cartilage overlay. Deutsche Gesell F Chir 29:460,1900; translater Dr F McDowell. In: Plast Reconstr Surg 1970;46:498-501.

19. Joseph J. Handbuch der spezielle chir. Kats, Preysing, Blumenfeld 1912.

20. Koenig F. 'Ueber Nasenplastik'. Brunsbeitr Z Klin Chir 1914;94:515.

21. Limberg A. Rhinoplasty with free transplantation from the auricle. Sovet Khir 1935;9:70-90.

22. Rethi A. Raccourcissement du nez trop long.' (Operation to shorten an excessively long nose). Revue de Chirurgie Plastique 1934;2:85.

23. Sercer A, Mundnich K. Plastiche operationen an der Ohrmuschel, Stuttgart G Rhiemeverlag, 1962. 
24. Rethi A. Operationen weyen entstellender sattelnase. Chirurg 1956;27:356-60.

25. Gillies HD. A new free graft applied to reconstruction of the nostril. Br J Surg 1943;30:305.

26. Brown JB, Cannon B. Composite free grafts of skin and cartilage from ear. Surg Gynec Obst 1946;82:253.

27. Goldman IB. New technique for corrective surgery of the nasal tip. AMA Arch Otolaryng 1953;58:183-87.

28. Anderson JR. A new approach to rhinoplasty. Trans Am Acad Ophth and Otol 1966;70:183-92.

29. Padovan L. External approach in rhinoplasty (decortication). Symp Orl Iug 1966;3-4:354-60.

30. Goodman WS. External approach to rhinoplasty. Can J Otol 1973;2:207-10.

31. Goodman WS, Charbonneau PA. External approach to rhinoplasty. Laryngoscope 1974;84:2195.

32. Freeman BS. Reconstructive rhinoplasty for rhinophyma. Plast Reconstr Surg 1970;46:265-70.

33. Dingman R, Walter C. Use of composite ear grafts in correction of the short nose. Plast Reconstr Surg 1969;43:117-24.

34. Walter C. The use of composite grafts in the head and neck region: In: English G (Ed). Otolaryngology, Philadelphia, Harper and Row 1981.

35. Sheen JH. Achieving more nasal tip projection by the use of a small autogenous vomer or septal cartilage graft. Reconstr Surg 1975;56:35-40.

36. Meyer R. Nasal septal perforation and nostril stenosis. In: Goldwyn RM (Ed). The Unfavorable Result in Plastic Surgery. Boston: Little Brown and Co 1972.

37. Bull TR, Mackay IS. Augmentation rhinoplasty. Facial Plast Surg 1984;1(2):125.

38. Farrior RT. 'Special rhinoplasty techniques (Chap 40). In: Cummings C (Ed). Otolaryngology-Head and Neck Surgery. St Louis: CV Mosby Co 1986;1:751-84.

39. Stucker FJ. The auto-alloplast: An alternative in facial implantation. Otolaryngol Clin North Am 1982;15:161.

40. Stucker FJ Jr, Bryarly RC Jr, Shockley WW. Reconstructive rhinoplasty. Chap 41. In: Cummings C (Ed). Otolaryngology Head and Neck Surgery. Krause CJ (Ed). St Louis: CV Mosby Co, 1986l;1:785-810.

41. Anderson JR, Ries WR. Rhinoplasty: Emphasizing the external approach. New York: Thieme Inc 1986.

42. Goldman IB. The importance of medial crura in the nasal tip reconstruction. Arch Otolaryng 1957;65:143.

43. Kridel RWH, Konior RJ, Shumrick KA, Wright WK. Advances in nasal tip surgery: The lateral crural steal. Arch Otolaryngol Head Neck Surgery 1989;115:1206-12.

44. Tardy ME Jr. Graduated sculpture refinement of the nasal tip. Facial Plastic Surg Clin North Am 2004;12:51-80.

45. Guyuron B, DeLuca L, Lash R. Supratip deformity: A Closer Look. Plast Reconstr Surg 2000;105:1140-51.

46. Johnson CMJ, Godin MS. The tension nose: Open structure rhinoplasty approach. Plast Reconstr Surg 1995;95:43-45.
47. Walter C. Aspects of facial correction and reconstruction by using transplants (composite grafts and implants) with special reference to surgical membrane implants. Otolaryngol Head Neck Surg 1994;110(6):524-29.

48. Tellioglu AT, Cimen K. Turn-in folding of the cephalic portion of the lateral crus to support the alar rim in rhinoplasty. Aesthetic Plast Surg 2007;31(3):306-10.

49. Spielmann PM, White PS, Hussain SS. Surgical techniques for the treatment of nasal valve collapse: A systematic review. Laryngoscope 2009;119(7):1281-90.

50. Toriumi DM, Josen J, Weinberger M, Tardy ME Jr. Use of alar batten grafts for correction of nasal valve collapse. Arch Otolaryngol Head Neck Surg 1997;123(8):802-08.

51. Gruber RP, Nahai F, Bogdan MA, Friedman GD. Changing the convexity and concavity of nasal cartilages and cartilage grafts with horizontal mattress sutures, Part II: clinical results. Plast Reconstr Surg 2005;115(2):595-608.

52. Adamson PA, Litner JA, Dahiya R. The M-Arch model: A new concept of Nasal Tip Dynamics. Arch Facial Plast Surg 2006;8(1):16-25.

53. Toriumi DM. New concepts in nasal tip contouring. Arch Facial Plast Surg 2006;8(3):156-85.

54. Conrad K, Torgerson CS, Gillman GS. Applications of GORETEX Implants in Rhinoplasty Re-examined After 17 years. Arch Facial Plast Surg 2008;10(04):224-31.

55. Sazgar AA. Lateral crural setback with cephalic turn-in flap: A method to treat the drooping nose. Arch Facial Plast Surg 2010;12(6):427-30.

56. Apaydin F. Lateral Crural Turn-in Flap in Functional Rhinoplasty. Arch Facial Plast Surg 2012:14(2):93-96.

57. Dubeta KR. Dorsal Approach Rhinoplasty. Int J Otorhinolaryngol Clin 2013;5(1):1-23.

58. Dubeta KR. (Unpublished) Dorsal Approach Rhinoplasty: A Radical Approach to the Rigid Nose. First presented at AAFPRS (COSM) Spring Meeting, Palm Desert, California, April 13, 1992.

\section{ABOUT THE AUTHOR}

\section{Kenneth R Dubeta}

Clinical Assistant Professor, Department of Otolaryngology and Head and Neck Surgery, Division of Facial Plastic Surgery, University of British Columbia, Canada; Founding Director, Pan Asia Academy of Facial Plastic and Reconstructive Surgery (PAAFPRS)

Correspondence Address: Kenneth R Dubeta MD, Clinical Assistant Professor, Department of Otolaryngology and Head and Neck Surgery Division of Facial Plastic Surgery, Suite 300-1144 Burrard Street Vancouver, BC, Canada, V6Z 2A5, Phone: +1(604)689-1585 e-mail: info@drkendubeta.com 